\title{
Nuevas economías transformadoras
}

\author{
Arrate ARIN TAPIA \\ Responsable del área de Modelos Socio-Económicos de Eusko Ikaskuntza \\ arrate.arin@eusko-ikaskuntza.eus
}

DOI: $10.1387 /$ reves. 19505

Fecha de entrada: 02/05/2017

Fecha de aceptación: 04/06/2017

Sumario: Introducción. Metodología y alcance. La Economía Social. Ficha de la Economía Social. La Empresa Social. Las B Corporations. Ficha de la Empresa Social. La Economía Solidaria. Ficha de la Economía Solidaria. La Economía del Bien Común (EBC). Ficha de la Economía del Bien Común. La economía colaborativa. Origen y tipos de plataforma. Riesgos y controversias de la economía colaborativa. Hacia una economía colaborativa responsable. Ficha de la economía colaborativa. La economía circular y la economía verde. La economía circular. La economía verde. Ficha de la economía circular y la economía verde. Ecosistema de las nuevas economías transformadoras. Conclusiones. Bibliografía.

\section{Resumen:}

Las "Nuevas Economías» son propuestas emergentes que han nacido como respuesta a los grandes retos sociales y medioambientales, en el contexto de las oportunidades que plantean las nuevas tecnologías y la propia innovación social. Ante la proliferación de corrientes existente, éste artículo ha seleccionado aquellos movimientos que tienen un mayor carácter transformador de la economía, elaborando un pequeño marco teórico de cada uno de ellos.

De esta forma, se ha analizado el ecosistema de la Economía social, la empresa social y la Economía Solidaria. Frente a estas corrientes con más trayectoria, se han analizado movimientos emergentes, tales como la Economía del Bien Común, las Economías Colaborativas y la Economía Circular y Verde. A lo largo del artículo, se observan una serie de tendencias y elementos de convergencia entre estos movimientos, pero también sus diferencias y limitaciones.

\section{Palabras clave:}

Economías transformadoras, economía colaborativa responsable, economía circular, Economía del Bien Común. 


\title{
Laburpena:
}

«Ekonomia Berriak», erronka sozialei eta ingurugirokoei erantzuna ematen dieten proposamenak dira, teknologia berriek dakarten aukeren eta berrikuntza sozialaren testuinguruan sortzen ari direnak. Korronte hauek ugaritzearen aurrean, artikulu honetan ekonomia eraldatzeko gaitasun handiagoa duten mugimenduak aztertu dira, horietako bakoitzaren inguruko marko teoriko txiki bat eginez.

Honela, Gizarte Ekonomiak, Enpresa Sozialak eta Ekonomia Solidarioak osatzen duten ekosistema aztertu dugu. Ibilbide luzeagoko korronteen aurrean, sortzen ari diren mugimenduetara jo dugu, hala nola, Guztion Onerako Ekonomia, Ekonomia Kolaboratiboak eta Ekonomia Zirkularra eta Berdea. Artikulu honetan antzematen dira joera amankomunak eta bateratasunak, baina baita ere euren arteko diferentziak zein mugak.

\section{Hitz gakoak:}

Ekonomia eraldatzaileak, erantzunkizunezko ekonomia kolaboratiboa, Ekonomia zirkularra, Guztion Onerako Ekonomia.

\begin{abstract}
:
The term "New economies" refers to emerging proposals that arose as a response to the major social and environmental challenges, in the context of the opportunities presented by new technologies and social innovation. In view of the current proliferation of terms in this area, this article focuses on the concepts with a larger impact on economy, and provides a brief theoretical framework for each of them.

This allowed for an analysis of the ecosystem of Social Economy, Social Enterprise, and Cooperative Economy. In contrast with these longstanding trends, this article analyzed emerging movements, such as the Economy for the Common Good, Collaborative Economies, and Circular and Green Economies, and observed a series of trends and converging elements among them, but also stressed their differences and constraints.
\end{abstract}

\section{Keywords:}

Transforming economies, responsible collaborative economy, circular economy, Economy for the Common Good.

\section{Claves Econlit:}

A110, P510. 


\section{Introducción}

Nos encontramos ante una crisis multidimensional, no sólo de carácter económico o financiero, sino de carácter ecológico y medio-ambiental, de incremento de la desigualdad, de transformación y precarización del empleo y una crisis de cuidados, ante los que es necesario buscar nuevas alternativas de organización social y económica.

El discurso sobre la necesidad de un cambio de modelo socio-económico está ganando centralidad, si bien no existe consenso acerca de cuál debe ser la orientación a tomar. No obstante, en la última década han proliferado prácticas y teorías económicas que tratan de dar respuesta a dilemas y retos sociales y medioambientales de nuestra época. Existen multitud de movimientos que se agrupan en un nuevo término, difuso y confuso aún, que es el de «nuevas economías» ${ }^{1}$.

Tradicionalmente ha sido la Economía Social y Solidaria, dentro de su amplitud de miradas y enfoques quien ha cumplido el rol de abogar por otro tipo de economía, con otros valores y filosofía.

Hoy, surgen diversos movimientos y modelos en búsqueda de alternativas. Existen, además, algunos movimientos que tratan de buscar cierta convergencia entre todas ellas. Tal es el caso de NESI Forum, un Foro Global sobre Nueva Economía e Innovación Social, que reunió en abril de 2017 en Málaga a los principales representantes internacionales de los llamados Nuevos Movimientos Económicos (NEMs). Dicho Foro concluyó con la lectura y publicación de la Carta de Málaga, en la que se aboga por «co-crear una nueva economía más sostenible, justa, colaborativa y centrada en las personas» ${ }^{2}$.

Por su parte, REAS (Red de redes de Economía Alternativa y Solidaria) se configura como red y busca actuar de plataforma conjunta para diversos movimientos de Economía Social y Solidaria, y van «asimilando» diversos movimientos que promuevan los mismos principios (movimientos femi-

1 En este contexto, y en el marco del proyecto «Desarrollo socio-económico: sociedad y empresa vasca» del área de Modelos Socio Económicos, Eusko Ikaskuntza celebró, en septiembre de 2016, un Seminario bajo el título "Nuevas economías", con objeto de mostrar y debatir acerca de nuevos modelos socio-económicos y de empresa y las posibilidades que pudieran ofrecer los mismos para transformar nuestra economía. En el marco de este Seminario se elaboró un informe previo, así como una serie de conclusiones obtenidas en los grupos de discusión que tuvieron lugar. Este Seminario, aunque despertó mucho interés, resultó insuficiente para profundizar debidamente en la materia, tratándose además de un ámbito bastante novedoso sobre el que existe aún poca literatura académica. Este artículo pretende ser una pequeña aportación a la materia.

${ }^{2}$ El texto íntegro de la "Carta de Málaga» puede consultarse en el siguiente enlace: http:// neweconomyforum.org/Carta_de_Malaga.pdf 
nistas, ecologistas, de finanzas éticas, de decrecimiento, ciudades en transición, monedas locales, etc.).

Ante una proliferación de términos y de «nuevas economías», este artículo pretende categorizar, ordenar y enmarcar los distintos movimientos en base a una serie de criterios que expondremos en el siguiente apartado.

Dado que se trata de movimientos incipientes, no existe un término académico que englobe a todos ellos. En este trabajo hemos utilizado el término "Nuevas economías transformadoras», diferenciando así del término "Nueva Economía» y hemos añadido el apellido transformadoras, pues buscamos analizar aquellos movimientos que tratan de transformar el modo en que funciona el sistema económico, sus principios y motivaciones básicos. Y dentro del término, hemos incluido la Economía Social y Solidaria, que queremos analizar y comparar junto a estos nuevos movimientos $y$, por tanto, aunque no es precisamente nueva, la hemos incluido dentro del concepto general.

Constatamos que existe poca literatura académica sobre cada una de las propuestas o movimientos, y aún menos desarrollo teórico sobre lo que suponen todos ellos en conjunto y sus interrelaciones.

En ese sentido, a lo largo de este artículo haremos un análisis comparado de los distintos movimientos que buscan o generan una transformación del modelo socio-económico. Se buscará aclarar cuál es la ambición de cada movimiento, su aspiración principal, quién promueve la iniciativa, cuál es su principal aportación y en qué sentido contribuye a la transformación del modelo socio-económico. También será objetivo de esta investigación identificar determinados elementos y tendencias comunes en todos ellos, así como los elementos de divergencia o incompatibilidad.

\section{Metodología y alcance}

Para la selección de los modelos que son objeto de este estudio, hemos aplicado los siguientes criterios ${ }^{4}$ :

- Que dicho movimiento tenga un mínimo marco teórico y conceptual desarrollado.

${ }^{3}$ La utilización cada vez más creciente y extendida de las tecnologías de información y de la llamada Economía del Conocimiento parte de un número significativo de empresas que actúan en muy diversos sectores de la actividad económica, muchas de ellas, sin embargo, nuevas, pequeñas, de alta flexibilidad y denominadas .com, dio orígenes a fines de la década de los noventa del siglo $\mathrm{xx}$ al término «Nueva Economía».

${ }^{4}$ Inspirado en el artículo de Álvaro Porro "¿Qué son las Otras Economías? 
- Que dicho movimiento tenga un impacto real en el modelo socio económico y/o tenga cierta capacidad transformadora.

- Que existan proyectos reales y prácticas sobre las que observar.

La idea es analizar los movimientos que tienen a día de hoy un mayor impacto en la economía real, bien por la capacidad transformadora de la economía (aunque a día de hoy aún no la haya logrado transformar), bien porque ya está funcionando y queremos valorar en qué sentido lo hace. Siguiendo esta idea, se han seleccionado los siguientes movimientos:

- La Economía Social.

- La Empresa Social.

- La Economía Solidaria.

- La Economía del Bien Común.

- La Economías Colaborativa.

— La Economía Circular y la Economía Verde.

Cabe señalar que estos modelos han sido recientemente citados en un informe del Consejo Económico y Social Europeo como nuevos conceptos emergentes para la Economía Social ${ }^{5}$.

Sin embargo, reconocemos dejar de lado algunas teorías y movimientos que también pudieran tener un gran efecto transformador. Las que citamos a continuación entendemos que son más bien teorías económicas (más que modelos), muy importantes, porque nos ayudan a analizar la realidad desde otro prisma, y conviene tenerlas como referencia, pero dado que superan el alcance de este trabajo, no vamos a profundizar y valorar cada una de ellas:

- Economías Feministas.

-Economía ecológica.

-Economía positiva.

Y dejamos de lado también movimientos sectoriales o que responden a determinados colectivos que, aunque tienen impacto en la economía, no se plantean cambios estructurales o transformadores. Tal es el caso de:

—Economía naranja, centrada en las industrias culturales y creativas.

5 El informe «Recent evolutions of the Social Economy in the European Union», en su capítulo 3 cita los principales conceptos emergentes para la Economía Social, léase: la empresa social, el emprendimiento social y la innovación social, la Economía Colaborativa, la Economía del Bien Común, la Economía Circular, la Responsabilidad Social Corporativa y, por último, analiza el nivel de reconocimiento de los gobiernos a estos conceptos emergentes 
- Economía plateada, centrada en la cobertura de necesidades a la población envejecida y la generación de nuevas oportunidades de negocio derivadas de ello.

El análisis de las diferentes economías se ha llevado a cabo acudiendo a las fuentes bibliográficas principales de cada movimiento. Normalmente existe un organismo, asociación o una persona de referencia que es quien lidera el movimiento y quien emite los principales informes y referencias sobre la materia. Acudiendo a dichas fuentes, se ha elaborado un pequeño marco teórico de cada movimiento.

Después se han elaborado una serie de fichas, para homogeneizar la información y facilitar la obtención de conclusiones acerca de las convergencias y divergencias entre todos los movimientos. Los aspectos recogidos en cada una de las fichas son:

-Categorización: En función de la escala y ambición de cada movimiento, hemos definido 3 categorías. Algunos movimientos cumplen simultáneamente más de una categoría. Explicamos aquí cómo se ha considerado cada una de ellas:

- Modelo Socio-Económico = Se trata de movimientos que tratan de transformar el modelo socio-económico en su conjunto. Tienen una visión macro-económica y se constituyen como posibles alternativas al sistema capitalista.

- Modelo de Empresa / Modelo de Negocio = La propuesta se centra en un nivel más micro de modelo de empresa o modelo de negocio. Cuando hablamos de modelo de empresa nos referimos a la propiedad, a las relaciones capital-trabajo y entre agentes, y a la toma de decisiones. Cuando hablamos de modelo de negocio nos referimos a la manera de combinar los factores para crear valor, es decir, la propuesta de valor (económica, por lo general, pero no únicamente).

- Sistema de acreditación / auditoría = Hemos constatado que muchos movimientos han generado su propio sistema de certificación o auditoría, su propio sistema de medición o valoración del éxito. En algún caso, puede suceder que éste sea el aspecto que adquiere mayor relevancia, cosa que entendemos no debería suceder, ya que el sistema de evaluación no es más que una herramienta al servicio de un fin más elevado.

- Generación de valor. Se han recogido tres dimensiones:

- Valor económico: entendido en sentido amplio, no sólo monetario, sino de satisfacción de necesidades de una forma eficiente. 
- Valor medioambiental: que contribuya de forma positiva a la preservación del capital natural. Se ha valorado si la propuesta gestiona los recursos de forma más ecológica que el actual sistema económico, sin entrar a valorar si ello es suficiente o no.

- Valor social: Que contribuye a reducir las desigualdades, y es un sistema que promueve la justicia y la equidad.

- Distribución de valor: Se ha valorado cómo se distribuye el valor que se crea, es decir, la redistribución. Se observa si existe una tendencia a la concentración de la riqueza generada o, por el contrario, el sistema promueve una mayor distribución entre los agentes concernidos.

— Impulso / Liderazgo: Se señala el origen del movimiento y qué organismo, persona o colectivo promueve actualmente la iniciativa.

- Relaciones de poder / Gobernanza: Está relacionado con la redistribución, pero en este apartado se observa cómo se toman las decisiones. El carácter más horizontal (participativo) o vertical de la iniciativa.

—Escalabilidad: dado que se trata de movimientos, en su mayoría, incipientes o minoritarios, se ha querido valorar la posible replicabilidad y escalabilidad de la iniciativa. Es decir, si el modelo tiene la capacidad de expandirse y constituirse en una alternativa real.

- Valoración desde el punto de vista de la Economía Social y Solidaria (ESS): Para los movimientos emergentes, que no nacen directamente de la ESS; se ha realizado una valoración en base a los criterios de la ESS.

Para finalizar, se ha realizado un análisis comparado y se concluye cuáles son las tendencias comunes y posibles convergencias y cuáles son las incompatibilidades entre las diferentes economías, así como las oportunidades de innovación para la Economía Social a partir de estos conceptos y modelos emergentes.

\section{La Economía Social}

Las iniciativas de economía basadas en la cooperación y la ayuda mutua han estado presentes en todas las épocas y civilizaciones, en forma de asociaciones y mutualidades. Se suele citar como el nacimiento del movimiento cooperativo a los pioneros de Rochdale en 1844, un grupo de 28 trabajadores de la industria textil que vivían en este pueblo, que trataron de controlar su destino económico formando una cooperativa llamada la Rochdale Equitable Pioneers Society, en cuyos estatutos citaban ya 
7 principios básicos del cooperativismo. Pocos años más tarde, en 1895 se crea en Londres la Alianza Cooperativa Internacional, en la que se recogen los valores y principios básicos del movimiento cooperativo. Más recientemente, la Social Economy Europe (SEE) en 2002 formula así los principios básicos de la Economía Social:

I. Primacía de la persona y del objeto social por encima del capital.

II. Adhesión voluntaria y abierta.

III. Control democrático ejercido por sus miembros (excepto para las fundaciones, que no tienen socios).

IV. Conjunción de los intereses de los miembros usuarios y del interés general.

V. Defensa y aplicación de los principios de solidaridad y responsabilidad.

VI. Autonomía de gestión e independencia respecto de los poderes públicos.

VII. Destinos de la mayoría de los excedentes a la consecución de objetivos a favor del desarrollo sostenible, del interés de los servicios a los miembros y del interés general.

CIRIEC-Internacional es la principal referencia académica de estudios acerca de la Economía Social. Esta entidad subdivide la Economía Social en dos subsectores: subsector de mercado y subsector de no mercado.

- Subsector de mercado: conforman el núcleo duro de este sector, formado por las cooperativas y mutualidades. Son entidades que se crean para satisfacer las necesidades de sus socios, operan en el mercado vendiendo productos y servicios, y pueden distribuir excedentes entre sus socios, pero no en proporción al capital aportado, sino de acuerdo con la actividad que cada uno desempeña.

- Subsector de no mercado: conformado por las asociaciones y fundaciones, ofrecen servicios a precios no significativos, no tienen ánimo de lucro, y por tanto, no pueden repartir excedentes.

El artículo de Pérez de Mendiguren, Etxezarreta y Guridi (2012) profundiza en los debates en torno a la delimitación del concepto. Uno de los debates se centra en si la delimitación debe hacerse en base a las formas jurídicas o bien se debe poner el acento en el objetivo social dando cabida también a empresas sociales. En ese mismo sentido, encontramos entidades de economía social en las que, aun manteniendo determinada forma jurídica, su forma de actuar y sus principios se ven diluidos. Tal es el caso de mutualidades que se han convertido en organizaciones "para-estatales» o grandes cooperativas industriales que operan en el mercado con criterios puramente competitivos. 
Ficha de la Economía Social

\begin{tabular}{|c|c|}
\hline Ejes de análisis & Economía Social \\
\hline Categorización & $\begin{array}{l}\square \text { Modelo Socio-Económico. } \\
\square \text { Modelo de Empresa. } \\
\square \text { Sistema de certificación / Auditoría de empresa. }\end{array}$ \\
\hline \multicolumn{2}{|c|}{ Generación de valor } \\
\hline $\begin{array}{c}\text { Valor } \\
\text { económico }\end{array}$ & $\begin{array}{l}\text { Las entidades de Economía Social que operan en el mercado } \\
\text { ofrecen bienes y servicios a precios competitivos. En la CAV, el } \\
\text { peso de la Economía Social ha sido de un } 10 \% \text { del empleo en } \\
2015^{6} \text {. } \\
\text { La Economía Social está presente en muchos sectores económi- } \\
\text { cos: industria, finanzas, educación, sector primario, etc. } \\
\text { Cabe destacar que se ha demostrado que estas entidades son más } \\
\text { resilientes frente a las crisis económicas, y que responden mucho } \\
\text { mejor al reto del mantenimiento del empleo en ciclos de crisis } \\
\text { económica. }\end{array}$ \\
\hline $\begin{array}{c}\text { Valor } \\
\text { medioambiental }\end{array}$ & $\begin{array}{l}\text { En sus orígenes la Economía Social no tiene una especial sensi- } \\
\text { bilidad por lo medioambiental. Surge para satisfacer las necesi- } \\
\text { dades (de trabajo, consumo...) de sus miembros. } \\
\text { Posteriormente, se ha incorporado el Desarrollo Sostenible en } \\
\text { los principios de la Economía Social. Y se constata que las for- } \\
\text { mas de Economía Social son idóneas para llevar a adelante pro- } \\
\text { yectos de colectivos con sensibilidad medioambiental. Tal es el } \\
\text { caso de cooperativas de consumo de energías renovables, agricul- } \\
\text { tura ecológica u otras (Goiener, Som Energía, etc.). }\end{array}$ \\
\hline Valor social & $\begin{array}{l}\text { Como su propio nombre indica, en la Economía Social prima el } \\
\text { objetivo social por encima de los intereses del capital. Además, } \\
\text { las formas de funcionamiento democráticas buscan el empode- } \\
\text { ramiento de sus miembros y la toma de decisiones basada en sus } \\
\text { propios intereses. } \\
\text { Destacamos aquí el subsector de no mercado, donde operan en- } \\
\text { tidades sin ánimo de lucro cuya finalidad es cubrir necesidades } \\
\text { sociales o de interés general. }\end{array}$ \\
\hline
\end{tabular}

${ }^{6}$ Dato obtenido del informe de Situación de la Economía Social Vasca 2015. Observatorio Vasco de Economía Social. Diciembre de 2016. 


\begin{tabular}{|c|c|}
\hline Ejes de análisis & Economía Social \\
\hline \multirow{4}{*}{$\begin{array}{l}\text { Distribución } \\
\text { de valor }\end{array}$} & Es una de las virtualidades de la Economía Social. \\
\hline & $\begin{array}{l}\text { La primacía del trabajo sobre el capital significa que la propiedad } \\
\text { es distribuida, de los socios. }\end{array}$ \\
\hline & $\begin{array}{l}\text { En el caso de las entidades que generan beneficios (cooperativas, } \\
\text { sociedades laborales), éstos se reparten entre los socios en base al } \\
\text { volumen de trabajo realizado y no en base al capital. }\end{array}$ \\
\hline & $\begin{array}{l}\text { Además, estas entidades cuentan con diversos mecanismos de } \\
\text { solidaridad y redistribución (intercooperación, compensación } \\
\text { de pérdidas, fondos destinados a educación y promoción social, } \\
\text { etc.) }\end{array}$ \\
\hline $\begin{array}{l}\text { Impulso / } \\
\text { liderazgo }\end{array}$ & $\begin{array}{l}\text { Se trata de un movimiento consolidado y arraigado, por lo que } \\
\text { cada tipología cuenta con algún organismo de promoción e im- } \\
\text { pulso del mismo, así como centros de investigación } 7 \text {. }\end{array}$ \\
\hline & $\begin{array}{l}\text { La gobernanza también es una de las características propias de la } \\
\text { Economía Social. }\end{array}$ \\
\hline $\begin{array}{l}\text { Relaciones } \\
\text { de poder / } \\
\text { gobernanza }\end{array}$ & $\begin{array}{l}\text { El principio de funcionamiento democrático y participativo, en } \\
\text { base a una persona un voto caracteriza a estas entidades. En con- } \\
\text { secuencia, el poder está distribuido y las relaciones son mucho } \\
\text { más horizontales que en otras entidades. Esto conlleva algunos } \\
\text { problemas operativos y de participación efectiva, pero no cabe } \\
\text { duda de que estas estructuras facilitan que el poder esté en ma- } \\
\text { nos de los miembros. }\end{array}$ \\
\hline & $\begin{array}{l}\text { Este modelo es replicable y trasladable a casi cualquier sector o } \\
\text { actividad económica. }\end{array}$ \\
\hline Escalabilidad & $\begin{array}{l}\text { El modelo de crecimiento es uno de los retos de estas entidades. } \\
\text { En sectores donde adquirir determinado tamaño se convierte en } \\
\text { factor clave de competitividad, se observa que surgen problemas } \\
\text { a la hora de mantener los principios cooperativos y de economía } \\
\text { social. También existe el problema de la financiación. En proyec- } \\
\text { tos intensivos en capital, estas entidades presentan dificultades }{ }^{8} \text {. }\end{array}$ \\
\hline
\end{tabular}

7 Véase en este enlace los principales centros de investigación y organismos de promoción de la Economía Social vasca: http://www.oves-geeb.com/es/enlaces

${ }^{8}$ El trabajo de Igor Ortega, publicado en Cuadernos Lanki n. ${ }^{\circ}$ 10, "Retos y dilemas del cooperativismo de Mondragón: tras la crisis de Fagor Electrodomésticos», profundiza sobre esta problemática. 


\section{La Empresa Social}

Este concepto aparece en Europa y Estados Unidos hacia los años 90. En 1996 surge la red Europea de Investigación EMES, y en Estados Unidos surge la «Social Enterprise Initiative» de la mano de la Universidad de Harvard, y más recientemente, el movimiento de las B Corporations. Existen diferencias entre estas tres corrientes.

El término de Empresa Social, con sus diversas visiones, es un término que ha sido promovido desde las instituciones para la búsqueda de soluciones innovadoras a problemas sociales y de exclusión. No obstante, es un término difuso que permite diversas interpretaciones $y$, por tanto, a nivel académico es poco preciso.

El término de Empresa Social pone un mayor énfasis en la orientación de carácter comunitario, y en muchos casos, incorpora a diferentes tipos de colectivos entre sus miembros (no solamente sus socios). La cuestión prioritaria de la Empresa Social sería satisfacer determinadas necesidades sociales, independientemente de su forma jurídica. Por su parte, la Economía Social, en su esfuerzo de delimitación, ha puesto mucho énfasis en su funcionamiento democrático y, para ello, su forma jurídica. Sin embargo, desde CIRIEC ya se aboga por superar dicho corsé formal para atender a lo sustancial que es la actividad y el objeto social de la empresa.

A continuación, expondremos el movimiento de las B Corporations, que es un movimiento de empresas sociales certificadas, de reciente creación.

\section{Las B Corporations}

En 2006 un grupo de empresarios, profesionales y académicos estadounidenses fundaron una organización sin ánimo de lucro denominada B Lab? . La definición de B Corporation Se basa en la convicción de que la principal finalidad de cualquier tipo de empresa (incluidas las capitalistas) no puede ser generar beneficios a cualquier precio, y que el balance de las empresas debe incluir también el impacto social y medioambiental para evaluar correctamente la sostenibilidad de las actividades empresariales.

Y para ello, ha desarrollado un completo sistema de certificación para evaluar el impacto social y medioambiental de la actividad empresarial, que funciona en base a criterios de auditoría externa. El sistema de certificación

9 En su web www.bcorporation.net recogen la información principal sobre esta materia, sus fundadores, las empresas que apoyan la iniciativa. 
es una adaptación del Balanced scorecard (de Kapplan y Northon, 1996), donde variables e indicadores estarían interconectados permitiendo el análisis de la empresa como un sistema integrado. Se evalúan cinco ámbitos en la empresa: medioambiente, compromiso con los trabajadores, los clientes, la comunidad y la gobernanza. Cada ámbito se valora a través de diversos indicadores, y con todo ello se genera un índice. Si la empresa obtiene más de 80 puntos sobre 200, obtiene la certificación B Corp.

Algunos ejemplos de B Corps son la firma de ropa deportiva Patagonia (California), la empresa de construcción de viviendas Grupo Mía (Mexico), la plataforma Fotoraporto S.L. (Barcelona) o la consultoría BIKOnsulting (Vitoria).

Por lo tanto, la certificación $B$ Corps es una herramienta para que las empresas (sea cual sea su forma jurídica) incorporen principios y valores sociales y medioambientales, lo que supone incorporar en gran medida principios y valores cooperativos (Campos-i-Climent, V. 2016).

Actualmente existen alrededor de 1.800 empresas certificadas, mientras que aquellas que miden sus impactos alcanzan las 15.000. Esta gran diferencia se por el hecho de que la certificación se debe llevar a cabo por el equipo de auditores adheridos a B Lab, con el coste de consultoría que ello requiere.

Concluimos que, si bien el enfoque del movimiento B Lab es hacia la empresa capitalista, el modelo de empresa social y empresa de la economía social (cooperativas, etc.) obtendrá de forma natural una puntuación alta en algunos de los indicadores de la certificación, y que tendrán de forma natural mayores facilidades para certificarse.

Sin embargo, entendemos también que son las empresas capitalistas las que pueden tener una mayor necesidad de obtener un sello o certificado que muestre a sus stakeholders que están comprometidas con lo social y lo medioambiental.

Ficha de la Empresa Social

\begin{tabular}{c|l}
\hline Ejes de análisis & \multicolumn{1}{c}{ Empresa Social } \\
\hline Categorización & $\begin{array}{l}\square \text { Modelo Socio-Económico. } \\
\square \text { Modelo de Empresa. } \\
\square \text { Sistema de certificación / Auditoría de empresa (En lo que } \\
\text { respecta a las B Corporations). }\end{array}$ \\
\hline \multicolumn{1}{c}{ Generación de valor } \\
\hline Valor & $\begin{array}{l}\text { La Empresa Social genera una actividad económica, produce } \\
\text { bienes y servicios, con un alto nivel de autonomía (autosuficien- } \\
\text { cia) y crea empleo. }\end{array}$ \\
\hline
\end{tabular}




\begin{tabular}{|c|c|}
\hline Ejes $\mathrm{d}$ & Empresa Social \\
\hline \multicolumn{2}{|r|}{ Generación de valor } \\
\hline $\begin{array}{l}\text { Valor } \\
\text { medioambiental }\end{array}$ & $\begin{array}{l}\text { De manera similar a lo que hemos comentado para la Economía } \\
\text { Social, éste no es su fin principal. Pero entendemos que al perse- } \\
\text { guir fines sociales y buscar la innovación social, la empresa social } \\
\text { tendrá un mayor grado de sensibilidad medioambiental, y puede } \\
\text { acometer en algunos casos proyectos con finalidad medioam- } \\
\text { biental. }\end{array}$ \\
\hline Valor social & $\begin{array}{l}\text { La Empresa Social busca soluciones innovadoras a problemas so- } \\
\text { ciales y lidera procesos de innovación social. }\end{array}$ \\
\hline $\begin{array}{l}\text { Distribución } \\
\text { de valor }\end{array}$ & $\begin{array}{l}\text { La empresa social puede tener ánimo de lucro, pero se establece } \\
\text { cierta limitación a la distribución de beneficios. Su finalidad } \\
\text { principal no es el lucro, sino que pone el énfasis en la orienta- } \\
\text { ción de carácter comunitario, en el logro de un fin social. }\end{array}$ \\
\hline $\begin{array}{l}\text { Impulso / } \\
\text { liderazgo }\end{array}$ & $\begin{array}{l}\text { Como ya se ha citado que existen varias corrientes: } \\
\text { — La europea, con impulso de la red EMES. } \\
\text { — El enfoque americano «Social Entrepreneurship», con un ma- } \\
\text { yor énfasis en la persona emprendedora. } \\
\text { —El movimiento B Lab (B Corporations). }\end{array}$ \\
\hline $\begin{array}{l}\text { Relaciones } \\
\text { de poder / } \\
\text { gobernanza }\end{array}$ & $\begin{array}{l}\text { La Empresa Social busca incorporar a diferentes colectivos a } \\
\text { la gestión de la empresa. Busca hacerlo de forma participativa. } \\
\text { La diferencia frente a la Economía Social es que no se hace de } \\
\text { forma estatutaria o por imperativo jurídico. } \\
\text { Por tanto, puede darse el caso de que en la práctica la gober- } \\
\text { nanza de una empresa social sea horizontal, o bien, puede haber } \\
\text { casos de Empresa Social que, con fin social, se gobierna por cri- } \\
\text { terios más verticales. } \\
\text { Podemos concluir que, en la Economía Social, la forma jurídica } \\
\text { garantiza un alto grado de horizontalidad y reparto del poder, } \\
\text { mientras en la Empresa Social podemos encontrar mayor diver- } \\
\text { sidad. }\end{array}$ \\
\hline Escalabilidad & $\begin{array}{l}\text { Se busca la replicabilidad y el impacto a gran escala, especial- } \\
\text { mente en el enfoque americano. } \\
\text { El hecho de no limitar la propiedad a los miembros o usuarios } \\
\text { puede abrir la puerta a otro tipo de inversiones (business angels, } \\
\text { filántropos...) y favorecer proyectos que requieran mayor inten- } \\
\text { sidad de capital. }\end{array}$ \\
\hline
\end{tabular}




\section{La Economía Solidaria}

La Economía Solidaria nace del tronco común de la Economía Social. Reivindica una práctica alternativa de la economía, pasando de ser un fin en sí mismo a ser un medio para servir al desarrollo personal y comunitario. La economía solidaria se basa en una serie de principios y valores, que quedan recogidos en la Carta de principios de la Economía Solidaria publicada por REAS, y que son: equidad, trabajo, sostenibilidad ambiental, cooperación, no-lucratividad y compromiso con el entorno.

Desde el punto de vista de conceptualización teórica, existen dos corrientes principales, la europea y la latinoamericana. Para Pérez de Mendiguren, Etxezarreta y Guridi (2009), la economía solidaria europea ha experimentado un progresivo proceso de institucionalización, mientras la latinoamericana ha estado mucho más orientada a la crítica y al carácter transformador de este tipo de economía.

A nivel internacional la entidad que promueve la Economía Solidaria es RIPESS (Red Intercontinental de Promoción de la Economía Social y Solidaria) y a nivel estatal, y miembro de dicha red existe REAS (Red de redes de Economía Alternativa y Solidaria). Estas redes promueven la práctica de la economía solidaria, a través de la agrupación de todas las entidades que trabajan directamente en ella, la promoción de medidas y legislación adecuadas, la promoción de unas finanzas éticas, un mercado social, el consumo responsable y todo tipo de acciones de sensibilización y formación.

La Economía Solidaria actúa en tres dimensiones diferentes:

- La dimensión organizativa: una red de organizaciones que trabajan en base a una serie de principios y finalidades diferentes a las organizaciones tradicionales capitalistas.

- La dimensión teórica: un marco alternativo que ofrece otra forma de entender la economía. Una visión ética y humanista del pensamiento y la actividad económica que coloca a la persona y a la comunidad en el centro del desarrollo. La Economía Solidaria no configura una única visión, sino que recoge diferentes visiones alternativas de la economía, como la feminista o la ecológica, siempre que estén alineadas con una serie de principios.

- La dimensión política: la Economía Solidaria se erige como un proyecto político alternativo. Incorpora una clara voluntad de transformación social, para lo cual, promueve el debate social e intenta influir e incidir en la política. De esta forma, elimina la división teórica y práctica entre economía, sociedad y política.

Mencionamos aquí las principales diferencias entre la Economía Social y la Economía Solidaria, si bien, a menudo se habla de ambos conceptos con- 
juntamente bajo la denominación de Economía Social y Solidaria (ESS). Pérez de Mendiguren, Etxezarreta y Guridi (2009) profundizan en esta cuestión. Para ellos, una de las diferencias sustanciales radica en el fondo de los debates y preocupaciones de cada grupo. En la Economía Social la principal preocupación radica en cómo competir en el mercado, cómo lograr internacionalizarse y crecer, en definitiva, cómo competir en el mercado con las empresas capitalistas. Sin embargo, los debates en la Economía Solidaria se centran en cómo lograr combatir la pobreza, cómo construir modelos alternativos de economía y como construir una alternativa al modelo capitalista.

En segundo lugar, los mismos autores citan que la Economía Solidaria está mostrando una mayor dinámica creativa, incorporando nuevas concepciones en su seno tales como la cuestión de género, los sistemas de intercambio, la promoción de cadenas de valor solidarias, el comercio justo, el comercio responsable o las finanzas éticas.

\section{Ficha de la Economía Solidaria}

\begin{tabular}{c|l}
\hline Ejes de análisis & \multicolumn{1}{c}{ Economía Solidaria } \\
\hline \multirow{5}{*}{ Categorización } & $\begin{array}{l}\text { Q Modelo Socio-Económico. } \\
\text { Q Modelo de Empresa. } \\
\text { Vistema de certificación / Auditoría de empresa (La auditoría } \\
\text { social). }\end{array}$ \\
\hline \multicolumn{1}{c}{ Valor } \\
económico & $\begin{array}{l}\text { Generación de valor } \\
\text { Valor } \\
\text { duce bienes y servicios y crea empleo. Es difícil de cuantificar en } \\
\text { qué medida lo hace, aunque se trata aún de actividades bastante } \\
\text { minoritarias. }\end{array}$ \\
\hline medioambiental & $\begin{array}{l}\text { La Economía Solidaria tiene entre sus principios el de la sosteni- } \\
\text { bilidad ambiental. } \\
\text { Dentro de las diferentes corrientes de la Economía Solidaria en- } \\
\text { contramos la economía ecológica, la idea del decrecimiento y } \\
\text { las ciudades en transición. En definitiva, la Economía Solidaria } \\
\text { tiene entre sus preocupaciones responder al reto de los límites } \\
\text { biofísicos del planeta. }\end{array}$ \\
\hline Valor social & $\begin{array}{l}\text { En la Economía Solidaria la rentabilidad económica se subor- } \\
\text { dina al fin último que persigue, que es mejorar la calidad de vida } \\
\text { de las personas y poner la sostenibilidad de la vida en el centro. } \\
\text { Por tanto, se busca generar valor social y se persiguen una serie } \\
\text { de valores de justifica, equidad, solidaridad y democracia. }\end{array}$ \\
\hline
\end{tabular}




\begin{tabular}{|c|c|}
\hline Ejes de análisis & Economía Solidaria \\
\hline \multicolumn{2}{|r|}{ Generación de valor } \\
\hline $\begin{array}{l}\text { Distribución } \\
\text { de valor }\end{array}$ & $\begin{array}{l}\text { La mayoría de principios de la ESS llevan implícita la idea de } \\
\text { la redistribución. Tales son los principios de equidad, trabajo y } \\
\text { compromiso con el entorno. } \\
\text { Y de forma más clara, el principio de «no lucro» da lugar a la re- } \\
\text { distribución de resultados y la reinversión de excedentes en la } \\
\text { propia actividad. }\end{array}$ \\
\hline $\begin{array}{l}\text { Impulso / } \\
\text { liderazgo }\end{array}$ & $\begin{array}{l}\text { El impulso del movimiento se lleva a cabo a través de la lógica de } \\
\text { red. En el estado español encontramos las redes RIPESS, REAS } \\
\text { y XES (Cataluña) }\end{array}$ \\
\hline $\begin{array}{l}\text { Relaciones } \\
\text { de poder / } \\
\text { gobernanza }\end{array}$ & $\begin{array}{l}\text { Las entidades de Economía Solidaria por lo general adoptan for- } \\
\text { mas jurídicas propias de la Economía Social, y con ello, garanti- } \\
\text { zan una mayor horizontalidad y participación en la toma de de- } \\
\text { cisiones. } \\
\text { Además, el principio de equidad lleva a fomentar la igualdad de } \\
\text { derechos y oportunidades, lo cual tendrá un reflejo en las rela- } \\
\text { ciones de poder. } \\
\text { La Economía Solidaria busca la democratización de la economía, } \\
\text { desde lo local y desde abajo. Son buenas prácticas habituales los } \\
\text { procesos democráticos y asamblearios, las relaciones de proxi- } \\
\text { midad y el arraigo local. (Gómez Calvo y Gómez Álvarez Díaz, } \\
\text { 2016) }\end{array}$ \\
\hline Escalabilidad & $\begin{array}{l}\text { El principio de cooperación alude a la conformación de redes de } \\
\text { solidaridad. La Economía Solidaria aboga por un tipo de creci- } \\
\text { miento diferente, a través de redes, promoviendo las relaciones } \\
\text { de proximidad. A través de la replicabilidad de las experiencias, } \\
\text { busca expandir el movimiento, pero siempre desde lo local y } \\
\text { buscando procesos endógenos de movilización de las capacida- } \\
\text { des. La Economía Solidaria, como se ha mencionado, muestra } \\
\text { un gran potencial de innovación, generando actividades en sec- } \\
\text { tores nuevos como las finanzas, las telecomunicaciones, la ener- } \\
\text { gía... tratando de utilizar el consumo (responsable) como pa- } \\
\text { lanca para el cambio. } \\
\text { Creemos que este tipo de crecimiento, endógeno, local y de } \\
\text { proximidad, puede suponer una limitación en determinados } \\
\text { sectores y actividades (industria, por ejemplo). A día de hoy, la } \\
\text { Economía Solidaria tiene un peso en la economía real aún mo- } \\
\text { derado. }\end{array}$ \\
\hline
\end{tabular}




\section{La Economía del Bien Común (EBC)}

El movimiento Economía del Bien Común ha sido fundado e impulsado por Christian Felber, un joven profesor de economía de la Universidad de Viena, con la publicación en 2010 de la versión original de la obra «La economía del Bien Común», traducida al español en 2012. Junto a un grupo de empresarios, Felber desarrolló este modelo como una alternativa teórica al capitalismo de mercado y a la economía planificada. Aunque el modelo parte de unos criterios generales, se presenta como un modelo abierto que se debe ir construyendo de forma democrática.

La Economía del Bien Común (EBC) se basa en la necesidad de introducir en el marco teórico y en las prácticas empresariales todos los aspectos sociales y ambientales que quedan fuera de las prioridades del modelo actual. Para ello, propone redefinir el concepto de éxito económico. Propone una herramienta de medición del éxito de las empresas, y una serie de incentivos para las empresas que actúen conforme a los objetivos del bien común. Esta herramienta se denomina Balance del Bien Común.

Christian Felber, propone un cambio de valores, pasando de aquellos que priman hoy en día, el beneficio económico y la competitividad, a otros en los que prime el Bien Común y la cooperación. Para reforzar esta idea, Felber nos recuerda, que en muchas Constituciones se hace mención a que la finalidad última de la economía es servir al Bien Común ${ }^{10}$. Por tanto, se trata de transformar la economía real capitalista a dichos principios constitucionales.

De forma similar a la Economía Social y Solidaria, la EBC propone trabajar en tres planos ${ }^{11}$ :

- Plano económico: a través de la creación de una alternativa real. En este plano podemos destacar la creación de una Banca Democrática, y la adhesión y adopción de la metodología, de forma voluntaria, de multitud de empresas y municipios.

- Plano político: la EBC es también un movimiento político que presiona al gobierno para que los principios teóricos se plasmen definitivamente en leyes. En este sentido, si bien los avances son escasos, destacamos que la EBC ha sido objeto de un dictamen por parte del Comité Económico y Social Europeo.

10 La Constitución de Baviera, dice en su artículo 151 dice "Toda actividad económica sirve al bien común»

11 Véase apartado «Misión y Visión» de la web de la Economía del Bien Común: http:// economia-del-bien-comun.org/es/content/misi\%C3\%B3n-y-visi\%C3\%B3n 
- Plano social: la EBC es también una iniciativa de concienciación social. En este sentido, destacamos la creación de diversas asociaciones (Asociación para el Fomento de la Economía del Bien Común, la EBC Euskadi, EBC Zaragoza...), y los grupos de divulgación denominados "campos de energía».

La EBC propone 20 medidas $^{12}$, como punto de partida para el debate sobre un nuevo orden económico orientado al bien común:

1. Nuevos valores para la economía: confianza, cooperación, aprecio, democracia, solidaridad, frente al beneficio económico y la competencia.

2. Nuevo marco legal, que incentive a las empresas a trabajar por el bien común y a cooperar.

3. Nueva definición de éxito: El éxito económico no es medido por indicadores monetarios como el beneficio financiero o el PIB, sino por el «balance del bien común» (BBC - a nivel de empresas) y el «producto del bien común» (PBC - a nivel macro).

4. Incentivos y beneficios legales, para las empresas con un buen Balance del Bien Común.

5. El beneficio es un medio, no un fin.

6. Búsqueda del tamańo óptimo: las empresas dejan de tener incentivos para crecer ilimitadamente y buscarán tener su tamańo óptimo.

7. Colaboración empresarial: Como las empresas no buscan crecer ilimitadamente, buscan colaborar entre ellas.

8. Ingresos y patrimonios limitados: La brecha salarial máxima será de 10 a $1^{13}$. También se limita la propiedad privada, que será como máximo de 10 millones de euros y las herencias no superarán los 500.000 euros por persona. Los excedentes sobre estos límites se destinarán a un «fondo intergeneracional».

9. Limitación de poder a las grandes empresas. Las empresas grandes pasarán a ser parcial y gradualmente controladas por los empleados y la comunidad (no por los gobiernos).

10. Bienes comunales: De manera similar, las empresas públicas en los campos de la enseñanza, la salud, la acción social, mo-

12 Véase apartado «contenido» de la Economía del Bien Común http://economia-del-biencomun.org/es/content/contenido

13 Como se señala más adelante, Felber propone estas medidas como punto de partida. Se trata de unos valores de referencia que, en todo caso, serían objeto de profundos debates, y finalmente, adoptados de forma democrática. Los parámetros y límites que se señalan en los siguientes puntos deben ser entendidos de este modo. 
vilidad, energía y/o comunicaciones, es considerada como infraestructura básica, y son gestionadas como bienes democráticos.

11. Banca democrática: existe un banco democrático que, como los bienes comunales, sirve al bien común, y es controlado por el pueblo soberano, no por el Estado.

12. Comercio internacional: se establece una moneda para el comercio internacional y una zona de comercio justo (Zona del Bien Común) donde las empresas con mejor BBC tendrán menores tarifas aduaneras. A largo plazo, se aspira a crear una Zona del Bien Común global, aprobada por la ONU.

13. Desprivatización de la naturaleza: la naturaleza es de todos, no es propiedad privada. Se elimina así la especulación sobre la tierra.

14. Reducción de la huella ecológica: la BBC ofrece incentivos a las empresas que midan y reduzcan su huella ecológica.

15. Reducción de la jornada laboral: se reduce el horario de trabajo retribuido (entre 30 a 33 horas semanales), dejando más tiempo para la vida personal y familiar, así como trabajos voluntarios y participación política.

16. Año sabático: se propone ofrecer la posibilidad de disfrutar de un año sabático cada 10 años de dedicación profesional, que será financiado con un salario mínimo incondicional. Con esta medida se reduciría prácticamente el desempleo (del $10 \%$ en la Unión Europea).

17. Democracia directa y participativa: se propone como complementaria a la democracia representativa.

18. Convenciones democráticas: todas estas propuestas deberán discutirse en asambleas ciudadanas y finalmente ser votadas democráticamente.

19. Educación: se propone incluir estas otras materias como la educación emocional, ética, comunicación, educación democrática, experimentación de la naturaleza y sensibilización corporal.

20. Competencias de gestión: se requerirá otro estilo de liderazgo y de gerencia en las empresas.

Es importante señalar que la EBC como un modelo abierto. Se proponen estas 20 medidas como punto de partida para llevar a cabo un proceso participativo y democrático para la elección de los elementos básicos de ese nuevo orden económico.

En septiembre de 2015 el pleno del CESE aprobó el Dictamen del Comité Económico y Social Europeo "La Economía del Bien Común: un 
modelo económico sostenible orientado a la cohesión social». El CESE considera la EBC como un modelo económico viable, que fomenta una economía más ética basada en los valores europeos y en la responsabilidad social. Resalta el enfoque holístico de la EBC, que recoge los valores fundamentales de otras propuestas económicas: la Economía Social, la circular, la de la funcionalidad, la basada en recursos y la economía azul. Por último, propone la transición hacia un Mercado Ético Europeo que promoverá la innovación social, elevará la tasa de empleo y será beneficioso para el medio ambiente. Y para ello propone una serie de medidas como el etiquetado ético, la compra pública ética, el consumo responsable y la banca ética.

No cabe duda de que este dictamen es muy positivo para el desarrollo de la EBC. La principal debilidad de este dictamen es que no tiene un carácter normativo, sino únicamente emite opinión sobre la materia. Por otra parte, si bien todas las medidas que se proponen son positivas e impulsan un cambio de comportamientos en toda la economía, creemos que la mayoría de ellas se basan en fomentar la buena voluntad de las empresas y los consumidores. El dictamen no entra a valorar, ni siquiera cita, los aspectos más duros de la EBC como, por ejemplo, el establecimiento de límites a la propiedad y a la riqueza, el reparto del trabajo, etc.Sin embargo, creemos que es un primer paso importante que seguramente dará lugar a nuevas normas y reglamentos europeos.

Los logros de la EBC son todavía discretos en lo que se refiere a la práctica. Hay que tener en cuenta que se trata de un movimiento relativamente joven. La web del movimiento (en su versión en inglés) ${ }^{14}$ ofrece datos actualizados en marzo de 2017. En Euskal Herria, destaca la iniciativa de Orendain (Gipuzkoa) como municipio por el Bien Común, así como la Asocación para el fomento de la Economía del Bien Común EBC Euskadi.

Ficha de la Economía del Bien Común

\begin{tabular}{l|l}
\hline Ejes de análisis & \multicolumn{1}{c}{ Economía del Bien Común } \\
\hline & $\begin{array}{c}\square \text { Modelo Socio-Económico. } \\
\text { Categorización }\end{array}$ \\
& $\begin{array}{l}\square \text { Modelo de Empresa. } \\
\text { del Biena de certificación / Auditoría de empresa = La Matriz }\end{array}$ \\
\hline
\end{tabular}

14 Véase en https://www.ecogood.org/en/community/ 


\begin{tabular}{|c|c|}
\hline Ejes de análisis & Economía del Bien Común \\
\hline & Generación de valor \\
\hline $\begin{array}{l}\text { Valor } \\
\text { económico }\end{array}$ & $\begin{array}{l}\text { La EBC no propone formas concretas para la creación de valor } \\
\text { económico. Lo que hace es poner la actividad económica al ser- } \\
\text { vicio de un fin más elevado, que es servir al bien común y a las } \\
\text { necesidades de la sociedad. } \\
\text { A pesar de ello, la EBC hace tres propuestas concretas en lo eco- } \\
\text { nómico que conviene subrayar: } \\
\text { - Creación de una zona de comercio justo global. } \\
\text { - Potenciar la colaboración empresarial bajo valores éticos. } \\
\text { — Crear una Banca Democrática. } \\
\text { Aunque no tenemos evidencia de ello, la lógica hace pensar que, } \\
\text { en el marco de la EBC, en caso de aplicarse de manera global, } \\
\text { la producción de bienes y servicios experimentaría un retroceso. } \\
\text { Pero el mismo no conllevaría una pérdida de bienestar de las } \\
\text { personas. }\end{array}$ \\
\hline $\begin{array}{c}\text { Valor } \\
\text { medioambiental }\end{array}$ & $\begin{array}{l}\text { La EBC busca un orden económico que cuide el planeta. De las } \\
20 \text { propuestas de partida, } 3 \text { de ellas buscan claramente beneficiar } \\
\text { el planeta. } \\
\text { - Desprivatización de la naturaleza. } \\
\text { - Reducción de la huella ecológica. } \\
\text { - Incluir la experimentación de la naturaleza como parte de la } \\
\text { educación a los niños. } \\
\text { Además, hay otras medidas que buscan un cambio de valores en } \\
\text { el que la vida y la felicidad de las personas se logre por otras vías } \\
\text { diferentes al consumo. } \\
\text { Las empresas no tienen que crecer ilimitadamente sino buscar su } \\
\text { tamańo óptimo. Para las personas, medidas como reducir la jor- } \\
\text { nada laboral y disfrutar de un año sabático, se relacionan con un } \\
\text { estilo de vida más pleno y más desapegado de lo material. } \\
\text { Por último, la inclusión en la Matriz del Bien Común de un eje } \\
\text { de sostenibilidad ecológica es otra prueba de la apuesta de este } \\
\text { modelo por la sostenibilidad ambiental. }\end{array}$ \\
\hline Valor social & $\begin{array}{l}\text { La EBC se basa en valores que promueven la justicia, la ética y } \\
\text { los derechos humanos. } \\
\text { Lo hace en base a la limitación de la riqueza y las herencias, la } \\
\text { disminución de las brechas salariales y los derechos de participa- } \\
\text { ción (véase en los siguientes apartados). }\end{array}$ \\
\hline
\end{tabular}




\begin{tabular}{|c|c|}
\hline Ejes de análisis & Economía del Bien Común \\
\hline \multicolumn{2}{|r|}{ Generación de valor } \\
\hline $\begin{array}{c}\text { Distribución } \\
\text { de valor }\end{array}$ & $\begin{array}{l}\text { Creemos que las propuestas más radicales que hace la EBC vie- } \\
\text { nen precisamente por la vía de la redistribución. } \\
\text { La EBC introduce, además de la equidad y la redistribución, un } \\
\text { concepto que es el de "poner límites» a la riqueza. Existe un ratio } \\
\text { de sueldo máximo (supongamos que de } 1 \text { a } 10 \text { ) y un nivel de ri- } \\
\text { queza máxima (supongamos que } 10 \text { millones de euros). Todo lo } \\
\text { que excede esos límites va a un fondo intergeneracional. } \\
\text { Y de forma similar, las empresas que vayan tomando una dimen- } \\
\text { sión muy grande pasan progresivamente a depender de la ciuda- } \\
\text { danía, lo cual Felber denomina como "democratización de las } \\
\text { grandes empresas». A partir de un número de empleados, y de } \\
\text { forma gradual, el personal y la sociedad civil adquieren un por- } \\
\text { centaje de derechos de voto, para orientar la actividad de la em- } \\
\text { presa hacia el bien común. Y dado que adquieren poder y toman } \\
\text { decisiones, se vuelven responsables, tanto de los beneficios como } \\
\text { de las pérdidas. } \\
\text { Por lo tanto, concluimos que la EBC busca reducir las desigual- } \\
\text { dades sociales, ya que considera que las grandes desigualdades } \\
\text { son fuente de conflictos, desconfianza, violencia e infelicidad. }\end{array}$ \\
\hline $\begin{array}{l}\text { Impulso / } \\
\text { liderazgo }\end{array}$ & $\begin{array}{l}\text { Este movimiento tiene un origen muy claro que es el impulso } \\
\text { del economista austríaco Christian Felber, junto con un grupo } \\
\text { de empresarios austríacos, y posteriormente, las asociaciones y } \\
\text { seguidores del movimiento }\end{array}$ \\
\hline $\begin{array}{l}\text { Relaciones } \\
\text { de poder / } \\
\text { gobernanza }\end{array}$ & $\begin{array}{l}\text { Este es otro de los aspectos donde más incide la EBC: la demo- } \\
\text { cratización de la economía. Felber (2012) entiende que «ninguna } \\
\text { instancia debería ser demasiado poderosa en relación con las demás, } \\
\text { porque se acabaría la libertad, y en este caso, la libertad colectiva: la } \\
\text { democracia». } \\
\text { Para mejorar la democracia, Felber propone un modelo de tres } \\
\text { pilares: la democracia representativa, la democracia directa y la } \\
\text { participativa. } \\
\text { La idea se materializa a través del Pueblo soberano, las conven- } \\
\text { ciones, la banca democrática, la democratización de las grandes } \\
\text { empresas y la participación. }\end{array}$ \\
\hline
\end{tabular}




\begin{tabular}{|c|c|}
\hline Ejes de análisis & Economía del Bien Común \\
\hline & Generación de valor \\
\hline Escalabilidad & $\begin{array}{l}\text { La idea es bastante utópica, pero una de las cuestiones novedosas } \\
\text { de la EBC es que propone una alternativa global. Propone cam- } \\
\text { biar el sistema de incentivos, y modificar el funcionamiento del } \\
\text { Estado, del mercado y de las empresas. } \\
\text { De esta forma, la EBC se puede aplicar en empresas, ONGs, } \\
\text { municipios e incluso a nivel Estatal. En el nivel macro, el sis- } \\
\text { tema de medición (frente al PIB) sería el Producto del Bien Co- } \\
\text { mún, y a niveles más micro, el Balance del Bien Común. } \\
\text { En un plano teórico, la EBC podría ser escalable y replicable a ni- } \\
\text { vel planetario. Además, permite su aplicación de forma progresiva. } \\
\text { Por el momento, constituye más una propuesta teórica, con algu- } \\
\text { nas prácticas reales en determinadas empresas y organizaciones. }\end{array}$ \\
\hline $\begin{array}{l}\text { Valoración } \\
\text { desde la ESS }\end{array}$ & $\begin{array}{l}\text { Como señalan Gómez Calvo y Gómez-Álvarez Díaz (2016), la } \\
\text { ECB y la ESS son propuestas complementariass }{ }^{15} \text {. Estos autores } \\
\text { indican como elementos comunes los siguientes: la visión antro- } \\
\text { pológica basada en la persona como ser social y la importancia } \\
\text { de sus valores, la aspiración a construir un modelo económico } \\
\text { alternativo fundamentado en la democracia, el activismo social y } \\
\text { político y el cambio de modelo desde lo local. } \\
\text { Observamos que la ESS tiene un mayor bagaje y recorrido desde } \\
\text { un punto de vista práctico, mientras la EBC es un planteamiento } \\
\text { relativamente reciente. } \\
\text { Sin embargo, la EBC, a pesar de ser un planteamiento muy utó- } \\
\text { pico, tiene la virtualidad de poderse aplicar de forma gradual } \\
\text { y estar abierta a todo tipo de agentes económicos y políticos, } \\
\text { mientras la ESS es más exigente al exigir que los agentes cum- } \\
\text { plan con todos sus principios. } \\
\text { Por otra parte, entendemos que la EBC parte de un plantea- } \\
\text { miento más ambicioso, al proponer cambiar completamente las } \\
\text { estructuras de poder, el marco institucional y la legislación. } \\
\text { Consideramos, por tanto, ambas propuestas como complemen- } \\
\text { tarias. Profundizaremos en sus diferencias en el apartado de } \\
\text { «Ecosistema de las nuevas economías transformadoras». }\end{array}$ \\
\hline
\end{tabular}

15 En este mismo sentido, el Comité Económico y Social Europeo, en el citado informe "Recent evolutions of the Social Economy in the European Union» menciona la coincidencia entre los valores que promueve la EBC y los principios y valores de la ESS. 


\section{La Economía Colaborativa}

\section{Origen y tipos de plataforma}

La idea de la Economía Colaborativa comienza a difundirse en 2007 con el artículo «Economía Colaborativa» de Ray Algar y, posteriormente con el libro "Lo que es mío es tuyo: el auge del consumo colaborativo», de Rachel Bostman el año 2010. Es un movimiento que surge a raíz de la crisis económica y financiera, como una respuesta por parte de la sociedad civil a las dificultades para consumir productos y servicios. Hoy en día, el movimiento se agrupa en torno a la plataforma Ouishare, que organiza Congresos y Jornadas sobre la temática de forma periódica. En el mundo hispano, Albert Cañigueral es un autor de referencia, es el fundador y editor de la web consumocolaborativo.com y autor del libro «Vivir mejor con menos».

La economía colaborativa o, su término en inglés, sharing economy, se basa en crear espacios de encuentro (digitales en su mayoría) donde la gente con necesidades/intereses comunes realiza intercambios de valor (mediante plataformas que permiten comprar, vender, alquilar, prestar, intercambia o regalar). El uso de las tecnologías de la información aporta la confianza y reciprocidad necesarias, a la vez que reduce de manera drástica los costes de coordinación y transacción.

La economía colaborativa está experimentando un crecimiento exponencial ${ }^{16}$. Las actividades que más han proliferado tienen que ver con la movilidad, el turismo y las finanzas. Sin embargo, el abanico de actividades y negocios que encontramos en este tipo de economía es cada vez más amplio, con actividades creativas, formativas, de compra-venta de bienes, e incluso de gobernanza participativa.

Cañigueral (2016) expone cuáles son los beneficios de la Economía Colaborativa:

- Modelo de negocio. El modelo de negocio basado en «coordinar recursos distribuidos» (la función de network orchestrator) es netamente superior a los modelos tradicionales de gestión de recursos centralizados y crecimiento interno. Es decir, se trata de modelos de negocio altamente eficientes, que generan utilidad a sus clientes, y mayores beneficios a los creadores de las plataformas.

16 Reciente se ha publicado un estudio de la Fundación EY, realizado en iniciativa conjunta con la Asociación Española de Economía Digital (Adigital), la Fundación de Estudios Financieros, el Círculo de Empresarios y la Fundación Cotec, que asegura que este tipo de economía ya supone entre un 1 y un 1,4\% del PIB español, y que podría duplicarse de aquí a 2025, hasta alcanzar entre un 2 y un $2,9 \%$. 
- Beneficios para la sociedad y el medio ambiente:

- La economía colaborativa ha transformado el sentido de la propiedad, dándole un mayor valor al uso o acceso. Bajo este, se extiende la idea de que «es mejor usar algo que comprarlo». Y, por tanto, al usar y disfrutar del acceso a bienes, servicios e información, el deseo de posesión disminuye.

- Los ciudadanos se convierten en agentes económicos a pequeña escala. Se llevan a cabo intercambios a cambio de dinero, intercambios triangulados, en base a monedas sociales o sistemas similares, o bien préstamos o regalos. A través de estas prácticas se promueve la idea de la autosuficiencia y la noción de interdependencia en la sociedad.

- Se reduce el uso de recursos materiales (al reutilizarlos o utilizar excedentes). Un claro ejemplo es el uso de asientos vacíos en coches. Este punto es muy controvertido debido al posible «efecto rebote» que puede ocasionar la disponibilidad de bienes y servicios en estas plataformas. El efecto medioambiental (tanto en positivo como en negativo), o huella ecológica, es difícil de cuantificar y, por tanto, hay opiniones diversas en relación a este aspecto.

Dentro de la economía colaborativa operan actores muy diversos con propósitos diferentes. Atendiendo al propósito o misión de la plataforma, encontramos plataformas con clara orientación de lucro, otras con un mayor propósito social (empresa social), aquellas que no tienen fin de lucro, aquellas de ámbito más comunitario/local y por último, las promovidas por el sector público. En ese sentido. Cañigueral (2016) apunta que la discriminación en base al propósito/rol de los diversos actores de la economía colaborativa es muy relevante para un análisis y fomento de políticas públicas que favorezcan la tipología de actividades más responsables y desincentiven o dificulten las menos adecuadas.

Para conocer cuál es el peso específico de cada tipología de plataformas, hemos acudido al estudio elaborado por la OCU (2016), que hace un análisis social de las plataformas. Ésta nos habla de 3 tipos de plataformas, y el porcentaje en número de plataformas que se encuentra en cada tipología:

1. Plataformas orientadas a la conexión de usuarios en redes de relaciones basadas en intereses comunes y en su reputación virtual (46\%).

2. Plataformas orientadas a la transacción (28\%).

3. Plataformas orientadas a la comunidad, donde se plantean objetivos como mejorar la cohesión social o promover hábitos de consumo más sostenibles (26\%). No obstante, en España este porcentaje disminuye al 10\%. Destacan en esta categoría las plataformas Huertos Compartidos y La Colmena que dice Sí. 
Por lo tanto, concluye la OCU que, desde una perspectiva social, el verdadero valor de estas plataformas es la calidad de las conexiones que generan entre los usuarios y su capacidad de crear entornos seguros utilizando reglas, información de calidad, sistemas de reputación virtual, garantías o mediación. En consecuencia, se concluye que la mayoría de las plataformas realmente ofrecen a la gente una solución práctica en sus necesidades diarias, pero sólo una pequeña parte de ellas se plantea como misión la mejora social de la comunidad.

\section{Riesgos y controversias de la economía colaborativa}

La proliferación de plataformas de muy diversa índole, ha dado lugar a polémica y controversia en relación a este modelo económico. Señalamos aquí las principales razones:

- La Economía Colaborativa está contribuyendo al desmantelamiento de los derechos laborales, principalmente, en aquellas plataformas «bajo demanda» en las que se ofrecen servicios logísticos o de «microtareas». Trebor Scholz (2016) critica las terribles condiciones de trabajo de muchos «trabajadores y trabajadoras», que se encuentran a disposición de dichas plataformas, en función de la demanda de cada momento, pero no son considerados como trabajadores o lo hacen en régimen de autónomos, con la consiguiente pérdida casi total de protección social. Sucede además que, en la economía digital, hay tipos de trabajos que se ofrecen por internet de manera global, por lo que países con bajos salarios arrastran los precios a la baja, precarizando aún más a las personas que trabajan en dichas plataformas.

Muy recientemente, los «trabajadores» de la empresa Deliveroo han denunciado su situación de trabajadores dependientes y su situación de precariedad ${ }^{17}$. Esta ha sido la primera huelga de trabajadores de una empresa de la Economía Colaborativa.

- La sospecha de la competencia desleal y/o de economía sumergida. En ocasiones se critica el logro de beneficios adicionales por parte de los «prosumidores», beneficios que en muchos casos no tributan y se constituyen en una especie de competencia desleal con aquellas actividades formales donde los proveedores pagan sus impuestos y asumen costes de transacción elevados. Es necesario definir los parámetros que distinguen a una actividad profesional de una actividad privada u ocasional, y reconocer al "prosumidor» como un nuevo

17 Véase noticia en http://www.eldiario.es/catalunya/trabajo/repartidores-Deliverooconvocan-primera-economia_0_658985300.html 
tipo de actor económico definiendo reglas simples que delimiten las obligaciones tributarias y administrativas.

- Falta de claridad jurídica respecto a la responsabilidad de la plataforma en caso de conflictos entre cliente-proveedor. El informe de la OCU menciona diversas medidas que las plataformas deberían tomar para ofrecer mayor transparencia e información a los usuarios, así como mecanismos de reclamación adecuados.

- La cuestión de la privacidad y el tratamiento de los datos. En este sentido la OCU solicita a las plataformas que los usuarios sean «dueños» de su reputación virtual de forma que, en un futuro, sea posible transportarla desde unas plataformas a otras como una moneda social.

- Riesgo de crear oligopolios y monopolios. La Economía Colaborativa está dando lugar a la creación de grandes plataformas con un enorme negocio empresarial. Así, sucede que un movimiento que surge de una necesidad social y con un espíritu comunitario es absorbido por las grandes corporaciones, con el riesgo de pérdida de su función social.

Observamos que la mayoría de estos riesgos y controversias tienen su origen en una falta de regulación adecuada. Los legisladores y las administraciones públicas tienen un rol fundamental en generar normas y leyes que protejan a los usuarios y prosumidores, y que, además, promuevan el tipo de plataforma social, económica y medioambientalmente más responsable. Y para ello, ya se ha señalado, es importante exigir a las plataformas y a los gobiernos más trasparencia y evaluación de los impactos que generan.

\section{Hacia una economía colaborativa responsable}

Frente a los modelos de economía colaborativa más "extractiva», existen movimientos que promueven modelos más responsables. Cañigueral (2016) ofrece algunas referencias al respecto. Por un lado, el movimiento por una economía colaborativa procomún ${ }^{18}$, que se basa en los principios de producción colaborativa, relaciones entre iguales $\mathrm{P} 2 \mathrm{P}$, recursos compartidos y abiertos y el acceso libre. Tal es el caso de la Wikipedia y el software libre. Por otro lado, el movimiento denominado «cooperativismo de plataforma", que supone combinar lo mejor de las plataformas digitales con los principios cooperativistas internacionales. $\mathrm{Y}$ por último, señala la necesi-

18 Esta idea la ha desarrollado el grupo Barcelona Colaborativa, quienes han publicado el documento "Declaración procomuns y propuestas de politicas para la economía colaborativa procomún» (2016). 
dad de comprender los diferentes modelos de negocio que existen dentro del concepto «sharing economy» para lo cual los autores Boyd Cohen y $\mathrm{Pa}$ blo Muñoz proponen la metodología «Sharing Bussines Model Compass».

En las próximas líneas vamos a desarrollar la idea del Cooperativismo de plataforma como ámbito de oportunidad. El impulsor de esta idea es Trébor Scholz, y existe un movimiento en torno a la web platform.coop, que organiza eventos y difunde información sobre la materia.

El término cooperativismo de plataforma se refiere a una generación de plataformas, de propiedad cooperativa, con otro modelo de gobernanza más democrática y pensado para mejorar las vidas de los usuarios de las mismas. Supone llevar los principios cooperativos más genuinos al mundo digital.

Teniendo en cuenta la gran tradición cooperativa, el conocimiento y experiencia sobre cooperativismo, que tenemos en Euskal Herria, creemos que es un ámbito a explorar. De hecho, el CESE publicó un dictamen sobre la Economía Colaborativa en enero de 2014 «el cooperativismo puede convertirse en el principal aliado del consumo colaborativo-participativo, en la medida en que conjugan y comparten principios y valores». Y del mismo modo, el reciente informe europeo sobre Economía Social ${ }^{19}$, así como el think tank británico New Economics Foundation ${ }^{20}$, mencionan el cooperativismo de plataforma como una propuesta a fomentar.

Trebor Scholz describe los tipos de cooperativas de plataforma:

\begin{tabular}{l|l}
\hline \multicolumn{1}{c|}{ Tipología / Definición } & \multicolumn{1}{c}{ Ejemplos } \\
\hline $\begin{array}{l}\text { Plataformas de intermediación la- } \\
\text { boral on-line de propiedad coope- } \\
\text { rativa. }\end{array}$ & $\begin{array}{l}\text { Loconomics (San Francisco), es una coopera- } \\
\text { tiva propiedad de freelancers. Ofrece masajes } \\
\text { y otros servicios solicitados localmente. } \\
\text { Son cooperativas que ofrecen servi- } \\
\text { cios profesionales a demanda. }\end{array}$ \\
$\begin{array}{l}\text { Fairmondo (Alemania) con 2.000 socios que } \\
\text { pretende convertirse en la alternativa de eBay, } \\
\text { donde los vendedores son copropietarios de } \\
\text { la organización. } \\
\text { Up \& Go (USA) ofrece servicios profesio- } \\
\text { nales a domicilio, como limpieza doméstica. } \\
\text { Minetras las plataformas extractivas de servi- } \\
\text { cios a domicilio se quedan con hasta un 30\% } \\
\text { de los ingresos de los trabajadores, Up \& Go } \\
\text { sólo cobra el 5\% que necesita para mantener } \\
\text { la plataforma. }\end{array}$ \\
\hline
\end{tabular}

19 Informe «Recent evolutions of the Social Economy in the European Union».

20 Informe "Building a new economy where people really take control. An agenda for change», NEF 


\begin{tabular}{l} 
Tipología / Definición \\
\hline Cooperativas de plataforma de pro- \\
piedad municipal. \\
Se trata de plataformas de propie- \\
dad pública. Muy aconsejables para \\
regular la oferta de servicios turísti- \\
cos, evitar la saturación y lograr un \\
beneficio común para la población \\
local.
\end{tabular}

Plataformas propiedad de los «producers» (usuario y productor).
Munibnb, es aún una propuesta. La idea es crear una plataforma que compita con Airbnb, de propiedad municipal, donde las tarifas serían para los anfitriones y una parte se destinaría al propio municipio.

Allbnb propone que los residentes reciban un dividendo de los beneficios de tales plataformas de alquiler.

Resonate (Berlin), un sistema cooperativo de streaming de música propiedad de las personas que lo utilizan.

Stocksy (Canada) es una cooperativa de archivo fotográfico propiedad de los fotógrafos. Les permite decidir por sí mismos cómo gestionar la empresa y obtener más beneficios por foto vendida a través de Internet.

Goteo (España), cooperativa de crowdfunding.

SomMobilitat (Cataluña), cooperativa que promueve la movilidad eléctrica y colaborativa.

Trans Union Care (New Jersey), los conductores forman parte de un sindicato y se benefician de ciertas coberturas.

Union Taxi (Denver), una cooperativa propiedad de los conductores.

App-Based Drivers Association (California) es una organización sin ánimo de lucro que unifica a los conductores de Uber, Lyft, Sidecar y otras compañías para ejercer presión y lograr una regulación favorable a los conductores.

La'Zooz (Israel) es una red para compartir transporte de forma totalmente descentralizada, con uso de una moneda digital, que denominan «cryptotokens». Cualquier conductor puede acoger compañeros de viaje y ganar «cryptotokens».

Fuente: elaboración propia a partir de Trebor Scholz (2016). 
El mismo autor hace otra aportación fundamental definiendo diez principios del cooperativismo de plataforma:

1. Propiedad: Cuando se habla de economía colaborativa, se suele hacer mención a la pérdida de interés por la propiedad (de los bienes), al tener una mayor facilidad de acceso a los mismos. Pero aquí no se refiere a eso, aquí se refiere a la propiedad de las propias plataformas, en definitiva, la propiedad de Internet. Se refiere a que las plataformas que generan valor gracias a las personas que las utilizan, sean propiedad de dichas personas.

2. Pago decente y seguridad de renta: Los trabajadores digitales merecen tener un salario y unas condiciones de trabajo dignas.

3. Transparencia y portabilidad de datos: Las plataformas deben ser trasparentes, no sólo en su operativa y en su gestión, también en el tratamiento de los datos de los usuarios.

4. Apreciación y reconocimiento: Se refiere a que los trabajadores digitales puedan comunicarse directamente con los gestores de las plataformas o sus propietarios y que reciban el reconocimiento que merecen.

5. Decisiones colectivas en el trabajo: Que los trabajadores se impliquen en decisiones acerca del diseño y usabilidad de la propia plataforma.

6. Un marco legal protector: El cooperativismo de plataforma necesita un marco regulatorio que le favorezca, y no al contrario.

7. Protección transferible de los trabajadores y prestaciones: Crear un sistema por el cual cada trabajador tenga una cuenta de seguridad social, a la que se le cotiza, proporcionalmente a los trabajos realizados en diferentes plataformas. De esta forma, todos los trabajadores estarían en igualdad de condiciones, lo cual desincentiva a las empresas a contratar "por horas» o «a demanda», pues ya no supondría una ventaja clara en costes.

8. Protección contra la conducta arbitraria: Existen plataformas en las que los usuarios valoran su experiencia y los trabajadores pueden ser despedidos únicamente por una mala valoración. Por otra parte, estos trabajadores van generando una reputación personal, pero cuando cambian de plataforma empiezan de cero. Se plantea la posibilidad de crear sistemas descentralizados de reputación e identidad.

9. Rechazo a la excesiva vigilancia en el lugar de trabajo. Una excesiva vigilancia resta dignidad a los trabajadores.

10. Derecho a desconectar. El trabajo digital también debe tener límites. No se puede estar disponible todos los días las 24 horas del 
día. Debe reconocerse el derecho a desconectarse de la red, y a no estar disponible.

Pero para lograr que el cooperativismo de plataforma se extendienda, hay que superar una serie de retos. Siguiendo el planteamiento de Scholz, señalamos aquí brevemente los principales retos y recomendaciones para el desarrollo del cooperativismo de plataforma:

— La autoorganización de los trabajadores digitales. Al no estar físicamente conectados, resultará más difícil la organización. Sin embargo, las redes sociales o aplicaciones (apps) pueden apoyar el que dichos colectivos se conecten.

- La generación de modelos. Para ello, se propone crear una primera ola de cooperativas y/o incubadoras, para posteriormente desarrollar todo un ecosistema cooperativo.

— Financiación de las plataformas cooperativas. La solución a este reto se encuentra en el crowdfunding (plataformas como Goteo) y en proyectos como seed.coop

- Modelo de crecimiento: Las plataformas cooperativas seguirán un modelo de crecimiento lento y buscarán la sostenibilidad del proyecto, aunque reconocen que es necesario lograr cierta escala.

- Código libre: El cooperativismo de plataforma apoya lo procomún. La idea sería crear un código para plataformas cooperativas, desarrollado con participación de los trabajadores. El desarrollo y generación de código es continuo y debería pensarse la fórmula de financiarlo.

- Uso de tecnología Blockchain, para abordar el tema de la confianza, y también para la toma de decisiones democráticas en las cooperativas.

- Las plataformas cooperativas deberían ser diseñadas de modo que se puedan generar actos de solidaridad (entre usuarios, entre trabajadores).

- Llevar a cabo prácticas laborales éticas.

- Formación y educación a los jóvenes en prácticas más cooperativas.

Como señala el citado informe de NEF (2016), es hora de retomar el control de la tecnología, la información y el trabajo. A través de estas propuestas de economía social, se puede recuperar el control de las plataformas para que éstas sirvan verdaderamente los intereses de sus usuarios ${ }^{21}$. Se

21 Sirva de ejemplo el caso de Deliveroo. Tras la huelga mantenida por los trabajadores de la plataforma, algunos de ellos están intentando crear una cooperativa de repartidores. Véase aquí: http://www.eldiario.es/catalunya/trabajo/Repartidores-vinculados-Deliveroo-Glovoocooperativa_0_691531775.html 
trata, por tanto, de una propuesta que busca una mayor democratización de la economía.

\section{Ficha de la economía colaborativa}

\begin{tabular}{|c|c|}
\hline Ejes de análisis & Economía Colaborativa \\
\hline Categorización & $\begin{array}{l}\square \text { Modelo Socio-Económico. } \\
\square \text { Modelo de Empresa (en este caso, modelo de negocio). } \\
\square \text { Sistema de certificación / Auditoría de empresa. }\end{array}$ \\
\hline \multicolumn{2}{|r|}{ Generación de valor } \\
\hline $\begin{array}{c}\text { Valor } \\
\text { Económico }\end{array}$ & $\begin{array}{l}\text { La EC es un modelo económico altamente eficiente. A través de } \\
\text { las nuevas tecnologías, logra casar oferta y demanda a un coste } \\
\text { muy bajo, reduce costes de intermediación, y logra generar la } \\
\text { suficiente confianza al «prosumidor». Por tanto, genera valor (y } \\
\text { beneficio) económico. La cuestión controvertida es cómo se dis- } \\
\text { tribuye el valor que se crea. }\end{array}$ \\
\hline $\begin{array}{l}\text { Valor } \\
\text { medioambiental }\end{array}$ & $\begin{array}{l}\text { La EC logra un uso más eficiente de los recursos existentes. La } \\
\text { facilidad de acceso hace que el mercado pierda interés por la } \\
\text { propiedad de determinados bienes, por lo que en cierta forma, } \\
\text { rompe con el paradigma del consumismo (acumulación y } \\
\text { compra ilimitada de productos), aunque puede tener un } \\
\text { efecto rebote. Al tener acceso a más bienes y servicios, se con- } \\
\text { sume más. Puede suceder claramente en el caso del turismo } \\
\text { (al facilitar el acceso, simplemente se viaja más). Por lo tanto, } \\
\text { no queda claro si se reduce huella ecológica. Si bien el mo- } \\
\text { delo tiene la virtualidad de poder hacerlo, éste tiene que venir } \\
\text { acompañado de una mayor conciencia por parte del consumi- } \\
\text { dor u otras medidas. }\end{array}$ \\
\hline \multirow{3}{*}{ Valor social } & $\begin{array}{l}\text { Según el informe de la OCU, sólo el } 26 \% \text { de las plataformas } \\
\text { tienen una verdadera orientación a mejorar la cohesión social } \\
\text { y promover hábitos de consumo responsables. Si bien todas las } \\
\text { plataformas son útiles para los usuarios, sólo una pequeńa parte } \\
\text { de ellas se plantea como misión la mejora social de la comuni- } \\
\text { dad. }\end{array}$ \\
\hline & $\begin{array}{l}\text { Por otra parte, y en el caso mayoritario de plataforma «extrac- } \\
\text { tiva», la merma de los derechos laborales y consiguiente precari- } \\
\text { zación puede considerarse como un gran coste social. }\end{array}$ \\
\hline & $\begin{array}{l}\text { Otra cuestión que no se suele tratar es la «brecha digital». Las } \\
\text { personas que no tienen acceso a estas plataformas (no tienen o } \\
\text { no saben utilizar Internet) no se podrán beneficiar. }\end{array}$ \\
\hline
\end{tabular}




\begin{tabular}{|c|c|}
\hline Ejes de análisis & Economía Colaborativa \\
\hline \multicolumn{2}{|r|}{ Generación de valor } \\
\hline $\begin{array}{r}\text { Distril } \\
\text { de }\end{array}$ & $\begin{array}{l}\text { A excepción de las plataformas cooperativas, por lo general, la } \\
\text { propiedad de las plataformas es privada y de alta concentración. } \\
\text { Las personas que crean las plataformas, aquellas que tienen éxito, } \\
\text { generan grandes plusvalías, para ellos mismos. } \\
\text { Además, en las plataformas más «extractivas», la eficiencia y va- } \\
\text { lor (económico) que se genera no se distribuye, en cualquier } \\
\text { caso, se reinvierte para ampliar y escalar aún más el negocio. Y } \\
\text { probablemente se produce cierta "evasión» fiscal, favorecida por } \\
\text { la desregulación y la ambigüedad sobre dónde se generan los in- } \\
\text { gresos. } \\
\text { En muchas de estas plataformas los «trabajadores independien- } \\
\text { tes» (como se les denomina) trabajan en condiciones verdadera- } \\
\text { mente vergonzosas (sin ningún tipo de cobertura legal). } \\
\text { Por su parte, las plataformas más responsables (cooperativas, co- } \\
\text { munitarias, municipales) cumplirían bien el objetivo de distribu- } \\
\text { ción de valor. } \\
\text { Para las plataformas "capitalistas», una buena regulación so- } \\
\text { bre los derechos laborales, así como la fiscalidad en caso de } \\
\text { ganancias (tanto para el prosumidor como para la propia pla- } \\
\text { taforma) sería una buena forma de mejorar el objetivo de dis- } \\
\text { tribución. }\end{array}$ \\
\hline $\begin{array}{l}\text { Impulso / } \\
\text { liderazgo }\end{array}$ & $\begin{array}{l}\text { A nivel teórico-académico, inicialmente surge en } 2007 \text { con el } \\
\text { artículo «Economía Colaborativa», posteriormente con el li- } \\
\text { bro «Lo que es mío es tuyo: el auge del consumo colaborativo». } \\
\text { Hoy en día, el movimiento se agrupa en torno a la plataforma } \\
\text { Ouishare. } \\
\text { En lo que respecta a la praxis, no existe un liderazgo como tal, } \\
\text { sino que proliferan plataformas creadas por start-ups y empren- } \\
\text { dedores del mundo digital. En España, la asociación española de } \\
\text { Economía Digital ha asumido la defensa de estos modelos de ne- } \\
\text { gocio. } \\
\text { Recientemente, en } 2015 \text {, ha surgido un movimiento que aboga } \\
\text { por las plataformas cooperativas que se denomina «Platform } \\
\text { cooperativism». }\end{array}$ \\
\hline
\end{tabular}




\begin{tabular}{|c|c|}
\hline Ejes de análisis & Economía Colaborativa \\
\hline \multicolumn{2}{|r|}{ Generación de valor } \\
\hline $\begin{array}{l}\text { Relaciones } \\
\text { de poder / } \\
\text { gobernanza }\end{array}$ & $\begin{array}{l}\text { Las relaciones entre particulares son horizontales. Tanto produc- } \\
\text { tor como consumidor están en igualdad de condiciones. } \\
\text { En cuanto al modelo de dirección, la mayoría de las plataformas } \\
\text { se gestionan según modelos de dirección centralizados (sin par- } \\
\text { ticipación en la gestión, ni en los beneficios ni en la propiedad, } \\
\text { por parte de los usuarios de las plataformas). Tal es así, que en } \\
\text { muchos casos la dirección de la plataforma está «escondida» y es } \\
\text { casi imposible poder comunicarse con la misma, sea en calidad } \\
\text { de usuario o como prestador de servicios. } \\
\text { Por su parte, las plataformas cooperativas abogan precisamente } \\
\text { por recuperar el control de internet y de las plataformas utili- } \\
\text { zando fórmulas de gobernanzas cooperativas y nuevas herra- } \\
\text { mientas tales como la tecnología Blockchain. }\end{array}$ \\
\hline Escalabilidad & $\begin{array}{l}\text { Los modelos de negocio de la economía colaborativa son fácil- } \\
\text { mente escalables y replicables. } \\
\text { Por lo tanto, el que proliferen aquellas plataformas más extrac- } \\
\text { tivas o, por el contrario, las más responsables e inclusivas, de- } \\
\text { pende de la acción de los gobiernos y la capacidad de la sociedad } \\
\text { de movilizarse a favor de estos últimos. }\end{array}$ \\
\hline $\begin{array}{l}\text { Valoración } \\
\text { desde la ESS }\end{array}$ & $\begin{array}{l}\text { Como ya se ha mencionado, existe una gran variedad de plata- } \\
\text { formas con diversidad de propósitos. } \\
\text { Las plataformas más conocidas y controvertidas (Uber, } \\
\text { Airbnb...) no cumplen ninguno de los principios de la ESS, } \\
\text { a excepción del compromiso medio ambiental, y con reservas } \\
\text { (ante la duda de que se produzca un efecto rebote) } \\
\text { Pero como se ha mostrado en este artículo, existen modelos de } \\
\text { EC responsable, como el del cooperativismo de plataforma, que } \\
\text { está totalmente en consonancia con los principios de la ESS, que } \\
\text { busca empoderar la ciudadanía, recuperar el control de Internet } \\
\text { y auto-organizarse para satisfacer sus necesidades y cuidar el en- } \\
\text { torno social y medioambiental. } \\
\text { Por tanto, la conclusión es que la ESS debe activarse y colaborar } \\
\text { en la creación de este tipo de plataformas responsables, coopera- } \\
\text { tivas y procomún. Y también participar y tratar de influir en el } \\
\text { diseńo de las políticas públicas que favorezcan este tipo de plata- } \\
\text { forma. }\end{array}$ \\
\hline
\end{tabular}




\section{La Economía Circular y la Economía Verde}

\section{La Economía Circular}

La evolución de la economía global ha estado dominada por un modelo de producción y consumo lineal, basado en el patrón «extraer-fabricar-desechar». Frente a dicho modelo lineal, la economía circular propone el patrón «rediseñar-reutilizar-reparar-reciclar». Este modelo económico trata en definitiva de desvincular el desarrollo económico global del consumo de recursos finitos. Conviene seńalar que el concepto de economía circular no es un concepto absoluto, y que lo que se trata es de lograr un mayor grado de circularidad en la economía. De hecho, la transición hacia una economía más circular exigirá cambios importantes en todos los agentes, desde las empresas, los gobiernos y organizaciones, hasta las personas consumidoras y, por tanto, la transición será gradual.

Las grandes escuelas de pensamiento de la economía circular surgen en los ańos 70, pero adquieren una mayor relevancia a partir de los años 90 . Existen diversas escuelas de pensamiento dentro de la economía circular: el diseño regenerativo, la ecología industrial, la biomímesis o la escuela de la economía azul, popularizada por el empresario belga Gunter Pauli ${ }^{22}$. Hoy en día, la entidad referente en la materia es la Fundación Ellen MacArthur creada en el año 2010, quien se dedica a investigar, difundir y divulgar todo el conocimiento y experiencias en torno a la economía circular. En el País Vasco, Innobasque (Agencia Vasca de Innovación), Aclima (Cluster vasco de industrias del medio ambiente) e Ihobe (Sociedad pública de gestión ambiental del Gobierno Vasco), han creado la red Circular Basque para promover e implementar la economía circular en Euskadi.

Por su parte, la Comisión Europea ha publicado diversas comunicaciones a favor de la Economía Circular, y la misma se está incorporando ya en las estrategias de especialización inteligente (RIS3) de muchas regiones europeas.

Los factores que han acelerado la necesidad de una economía más circular son:

— La escasez de materias primas.

— Volatilidad y aumento de los precios de las materias primas y la energía.

- Las tecnologías de la información que permiten un seguimiento eficaz de los materiales a través de la cadena de suministro y proporcio-

22 Su creador promueve la iniciativa a través de la web www.theblueeconomy.org y a través del think tank ZERI (www.zeri.org). 
nan datos accesibles sobre la composición, desmontaje o métodos de re-fabricación de un producto.

- Surgimiento de modelos de negocio que priorizan el acceso frente a la propiedad (cuestión que ya se ha citado en el apartado de economía colaborativa).

—Cambio en la actitud de los consumidores: mayor sensibilización y nuevos patrones de consumo.

Si bien el cambio en los patrones de consumo y las tecnologías facilitan la implantación de la economía circular, la razón de fondo para el desarrollo de la misma es la insostenibilidad del actual modelo de producción y consumo, así como los impactos ecológicos negativos que el mismo provoca.

La Economía Circular se basa en tres principios. Cada uno de ellos se refiere a una parte del ciclo material de energías y materias primas:

- Principio 1 = Preservar y mejorar el capital natural controlando las reservas finitas y equilibrando los flujos de recursos renovables. Las palancas para lograrlo son: la desmaterialización de la utilidad (cuando es posible), la regeneración del suelo y el uso de materiales y tecnologías renovables

- Principio 2 = Optimizar el rendimiento de los recursos, mediante la circulación de los productos, componentes y materiales en uso, a su máxima utilidad en todo momento en ambos ciclos, técnico y biológico. Esto implica diseñar para que los productos se puedan mantener, reparar y reciclar, logrando generar bucles internos más estrechos, priorizando el mantenimiento en lugar del reciclaje. En esta fase, los conceptos de compartir y reutilizar son fundamentales. ${ }^{23}$ En lo que se refiere al ciclo biológico, la economía circular trata de mejorar el rendimiento en el uso de materiales biológicos, así como la regeneración de los mismos.

- Principio 3 = Minimizar las pérdidas y externalidades negativas. Esto incluye reducir los dańos al sistema y la gestión de los residuos. Ya hemos seńalado, que no existe una economía totalmente circular, y por tanto, el sistema generará residuos, pero el objetivo será minimizarlos y reducir su impacto sobre el capital natural.

El ciclo de la economía circular y los tres principios que acabamos de exponer se ven de forma muy gráfica en la siguiente ilustración:

${ }^{23}$ La cuestión de compartir y reutilizar constituye un puente clarísimo entre la economía circular y la economía colaborativa. Volveremos sobre esta cuestión en las conclusiones. 


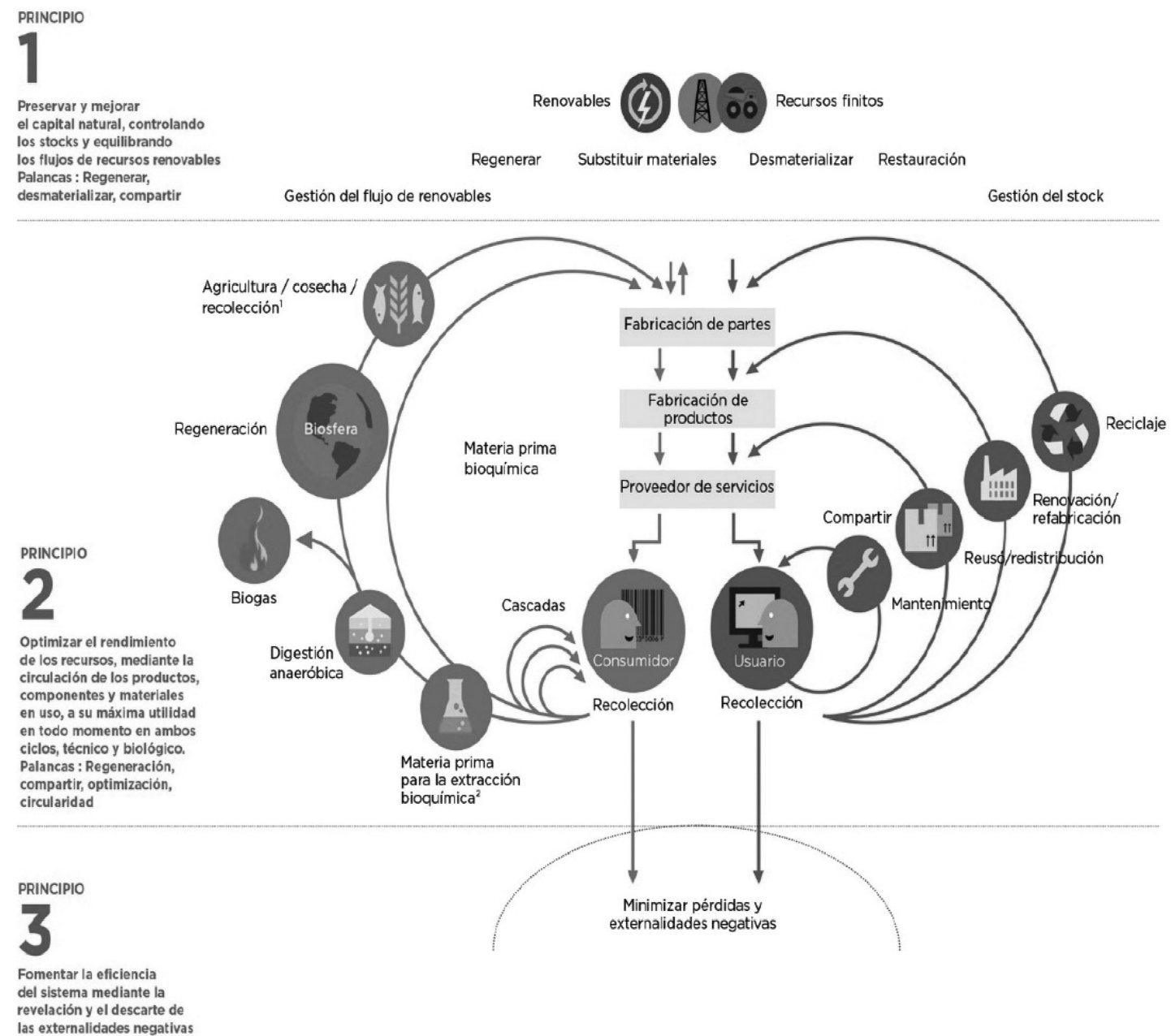

Fuente: dibujo de Braungart y McDonough, Cradle to Cradle, obtenido de Fundación Ellen MacArthur «Hacia una economía circular».

\section{Esquema de la economía circular}

La fundación Ellen MacArthur, SUN y McKinsey han desarrollado un estudio para medir los impactos económicos de una transición hacia una economía circular, con un escenario de aquí a 203024. Dicho estudio se centra en tres sectores prioritarios, pero las conclusiones son generalizables. Los sectores analizados son la movilidad, los sistemas de alimentación y la

${ }^{24}$ Se trata del informe Growth Within: a circular economy vision for a competitive Europe, Fundación Ellen MacArthur, SUN, McKinsey \& Co. (Junio de 2015), pero nos hemos basado en el resumen sobre el mismo publicado en Fundación Ellen MacArthur (2015) «Hacia una economía circular: motivos económicos para una transición acelerada» Disponible en: https://www. ellenmacarthurfoundation.org/assets/downloads/publications/Executive_summary_SP.pdf 
construcción. El estudio cita las siguientes oportunidades en la economía circular:

-Oportunidades económicas: Se estima que la economía circular generará un incremento de la productividad y crecimiento del PIB. Se lograrán ahorros en costes de materias primas, se generarían nuevos empleos, algunos intensivos en manos de obra (actividades de reciclaje, re-fabricación...) y otros de alta cualificación (diseño industrial, innovación organizativa...), y se generan oportunidades para la innovación tecnológica.

-Oportunidades medioambientales: se reducen las emisiones de dióxido de carbono, el consumo de materias primas y se reducen los residuos.

-Oportunidades para las empresas: Se reduce la dependencia hacia los costes de materias primas, se genera una mayor interacción y lealtad con los clientes, y nuevos modelos de negocio, como por ejemplo la refabricación de teléfonos móviles, alquiler de lavadoras de alta gama, reciclaje de ropa, fabricación de botellas de cristal reutilizable, etc.

-Oportunidades para los ciudadanos: tendrán una mayor renta disponible al contar con productos de mayor calidad y vida útil y otros modelos funcionales.

Hoy en día todavía, tanto el sistema económico como la normativa y el comportamiento general de empresas y consumidores favorece el modelo lineal. Pero existen una serie de tendencias disruptivas y una serie de palancas que deben aprovecharse para favorecer una transición hacia una economía más circular. La Fundación Ellen MacArthur, en su informe "Hacia una economía circular: motivos económicos para una transición acelerada» senala los siguientes:

—El diseño circular: Los productos y procesos deben diseñarse para su reutilización, reciclaje y paso en cascada de los productos.

- Nuevos modelos empresariales. El paso de modelos de propiedad a modelos de pago por uso (o rendimiento) darán lugar a nuevos modelos de negocio.

- Ciclo inverso. Se deben desarrollar sistemas de recogida en zonas accesibles para los clientes, así como tratamiento de materiales y cadenas de logística inversa para recolocar materiales y productos.

-Educación: Es necesario preparar a los futuros profesionales para este nuevo paradigma económico.

- Financiación: Estimular la financiación de infraestructuras e $\mathrm{I}+\mathrm{D}$, además del apoyo gubernamental, que debe mostrar su compromiso por llevar a cabo la transición hacia la economía circular. 
- Plataformas colaborativas: Pueden ejercer un rol fundamental en el intercambio de información entre sectores, facilitar la intermediación, sistemas conjuntos de recogida... además del desarrollo de modelos de negocio basados en el acceso y uso de productos (la economía colaborativa).

— Marco regulatorio: La fiscalidad y la regulación deberán favorecer la economía circular.

La transición tendrá una serie de costes, tanto desde el punto de vista de la inversión e I+D necesarios, como desde la visión de aquellos negocios y sectores que queden obsoletos.

La Comisión Europea, en su comunicación "Cerrar el círculo: un plan de acción de la UE para la economía circular» cita las principales palancas que hemos mencionado anteriormente. En lo que respecta al fomento de la innovación y la $\mathrm{I}+\mathrm{D}$, señala que muchas regiones europeas han incorporado la economía circular en sus estrategias de especialización inteligente, y hace referencia a una serie de sectores prioritarios, por sus características específicas, o por la huella ecológica que generan, o bien por la dependencia de materiales procedentes de fuera de Europa. Son los siguientes:

- Los plásticos.

- Los residuos alimentarios.

- Materias primas críticas (algunos metales, el fósforo, etc.).

- Construcción y demolición.

- Biomasa y bioproductos.

La Sociedad pública de gestión ambiental del Gobierno Vasco, IHOBE, ha publicado recientemente el informe «Iniciativas empresariales de economía circular en el país vasco. descripción de 36 proyectos» ${ }^{25}$.

$25 \mathrm{Al}$ margen del informe de Ihobe, también queremos hacer mención a la experiencia de la agencia de desarrollo de Lea Artibai, junto a Azaro Fundazioa. La Comarca se ha acercado a la "filosofía» de Blue Economy de la mano de su principal impulsor Gunter Pauli y actualmente la Comarca está inmersa en un proceso de identificación e implantación de proyectos empresariales medioambiental y económicamente sostenibles. Las prioridades de la comarca son: alimentación saludable, salud, turismo y bienestar, a través de la economía azul y el diseño sistémico.

Un ejemplo de ello es el producto Gaxure (www.gaxure.com), un producto con el que se aprovecha el $100 \%$ del lactosuero y que tiene un proceso de elaboración que no necesita grandes inversiones. Así, las queserías pueden producirlo de forma sencilla, diversificando su negocio y dando una salida al lactosuero que, de no aprovecharlo, genera impacto medioambiental negativo. 


\section{La Economía Verde}

El Programa Naciones Unidas para el Medio Ambiente (PNUMA) publicó en 2011 el informe "Hacía una economía verde. Guía para el desarrollo sostenible y la erradicación de la pobreza», en el cual define la Economía Verde como aquella que da lugar al mejoramiento del bienestar humano e igualdad social, mientras que se reducen significativamente los riesgos medioambientales y las escaseces ecológicas. Se considera, por tanto, como una herramienta para el desarrollo sostenible y la erradicación de la pobreza.

La idea central de la economía verde es preservar el capital natural invirtiendo en él, generar empleo a través de estas actividades económicas y reducir la pobreza, especialmente gracias a la inversión en el capital natural del que depende el bienestar de las poblaciones más desfavorecidas. Por ello, se pone el foco 10 sectores económicos prioritarios (para los países empobrecidos): agricultura, edificaciones, energía, pesca, silvicultura, industria, turismo, transporte, residuos y agua. El PNUMA prevé que la transición hacia una economía verde incrementaría el PIB mundial alrededor de una $2 \%$, pero al igual que sucede con la economía circular, esta transición generará pérdidas en algunos sectores que deberán ser compensados. Existen determinados «costes de transición» y la cuestión clave constituye en cómo gestionar la propia transición para no generar mayores desigualdades.

El PNUMA establece una serie de medidas que se deben tomar, principalmente por los gobiernos nacionales, para lograr la transición hacia la economía verde, tales como el establecimiento de marcos regulatorios adecuados, una fiscalidad verde, y principalmente, el acceso a financiación adecuada, para lo cual, además de apelar al sector privado, hace mención a los instrumentos multilaterales de desarrollo, y más concretamente, al Fondo Verde para el Clima y otros mecanismos incipientes.

Este «reverdecimiento» y el planteamiento institucional sobre Economía Verde ha sido objeto de críticas de ecologistas e indígenas que hablan del «Lavado verde» desde su inicio, y cobraron especial relevancia en la Cumbre Rio+20 de 2012, tanto por el fracaso de los objetivos de la reunión como por el planteamiento de fondo. A lo que es PNUMA defiende que la sostenibilidad no se obtiene únicamente a costa del progreso económico, y que la economía verde no es un lujo que sólo se pueden permitir los países ricos.

Concluimos, por tanto, que la Economía Verde es impulsada por Naciones Unidas (a través del PNUMA) con un triple objetivo de generación de riqueza, reducción de pobreza y recuperación del medio natural, que requiere de inversiones tanto privadas como públicas para llevar a cabo la transición. Por tanto, tiene un enfoque institucional y requiere de los ins- 
trumentos de ayuda al desarrollo. Desde un punto de vista teórico, es un planteamiento más holístico que el de la economía circular. La siguiente figura muestra este aspecto:

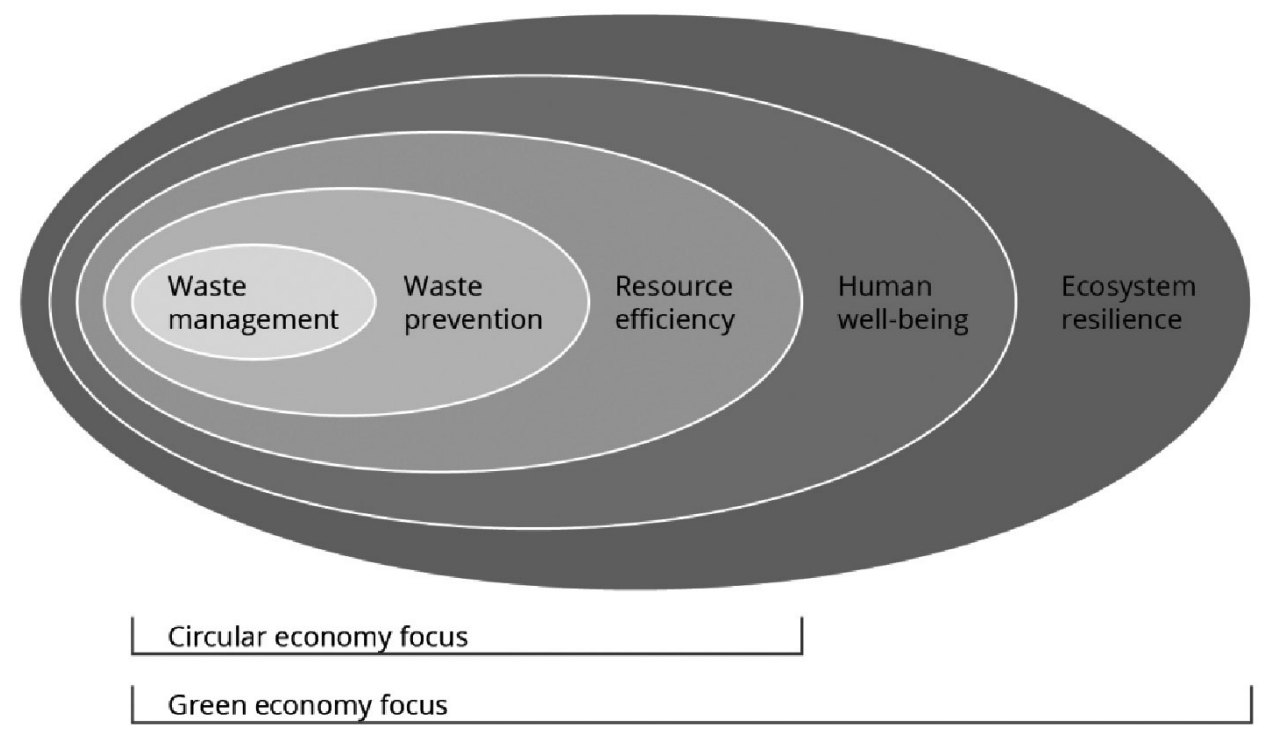

European Environment Agency

Fuente: Agencia Europea para el Medio Ambiente.

Mientras la Economía Circular se centra en optimizar los flujos de materiales y minimizar los residuos alargando la vida útil de productos y materiales, el enfoque de la Economía Verde es hacia el uso del agua, la energía, la tierra y la biodiversidad para asegurar el bienestar humano y la resiliencia de los ecosistemas. A priori, ambos planteamientos podrían o deberían integrarse, pero hasta la fecha, no se ha producido dicha hibridación de ambos modelos.

Entendiendo, por tanto, ambas propuestas como complementarias, vamos a recoger las conclusiones en una misma ficha, haciendo mención en cada caso a la verde o a la circular.

Ficha de la Economía Circular y la Economía Verde

\begin{tabular}{l|l}
\hline \multicolumn{1}{c|}{ Ejes de análisis } & \multicolumn{1}{c}{ Economía Circular y Verde } \\
\hline \multirow{3}{*}{ Categorización } & $\square$ Modelo Socio-Económico. \\
& $\square$ Modelo de Empresa (Modelo de negocio). \\
& $\square$ Sistema de certificación / Auditoría de empresa. \\
\hline
\end{tabular}




\begin{tabular}{|c|c|}
\hline Ejes de análisis & Economía Circular y Verde \\
\hline \multicolumn{2}{|r|}{ Generación de valor } \\
\hline $\begin{array}{l}\text { Valor } \\
\text { económico }\end{array}$ & $\begin{array}{l}\text { Como hemos señalado, tanto el informe de Ellen MacArthur } \\
\text { Foundation, la Comisión Europea, el PNUMA y el informe de } \\
\text { Ihobe señala los potenciales beneficios económicos de transitar } \\
\text { hacia una Economía Circular y Verde. } \\
\text { Tanto para la generación de nuevas actividades económicas, } \\
\text { como por el ahorro en recursos materiales y energía, como } \\
\text { en el hecho de que se trata de actividades generadoras de em- } \\
\text { pleo. }\end{array}$ \\
\hline $\begin{array}{c}\text { Valor } \\
\text { medioambiental }\end{array}$ & $\begin{array}{l}\text { La razón de ser y objetivo prioritario de este modelo, es transitar } \\
\text { del modelo lineal al circular. El modelo busca aplicar una visión } \\
\text { sistémica que modifique el actual modelo económico, hacién- } \\
\text { dolo más circular y preservar el capital natural. } \\
\text { Por su parte, la Economía Verde pone el foco en la mejora del } \\
\text { bienestar de las personas preservando los ecosistemas, especial- } \\
\text { mente, en países en vías de desarrollo, como forma para reducir } \\
\text { la pobreza. }\end{array}$ \\
\hline Valor social & $\begin{array}{l}\text { La economía circular no hace una mención especial a la proble- } \\
\text { mática social. Por su parte, la economía verde busca, a través de } \\
\text { las nuevas actividades «verdes», generar actividad económica y } \\
\text { reducir la pobreza. }\end{array}$ \\
\hline $\begin{array}{l}\text { Distribución } \\
\text { de valor }\end{array}$ & $\begin{array}{l}\text { La economía verde genera puestos de trabajo y reduce la depen- } \\
\text { dencia de importaciones (en países en vías de desarrollo). } \\
\text { Se hace mención a la generación de actividad económica, sin de- } \\
\text { tallar quién lidera dichas actividades y cómo se reparten los be- } \\
\text { neficios creados por las mismas. } \\
\text { Por su parte la economía circular no menciona aspectos redis- } \\
\text { tributivos. Lo que sí mencionan ambos modelos son los efec- } \\
\text { tos de la transición del modelo lineal al verde-circular, que ge- } \\
\text { nerarán cambios en los modelos de negocio, los consumidores y } \\
\text { los países y se producirán efectos redistributivos. Resultará cru- } \\
\text { cial tener en cuenta y paliar estos efectos, algo que la Fundación } \\
\text { Ellen MacArthur denomina «reequilibrio de los efectos redistri- } \\
\text { butivos» }\end{array}$ \\
\hline
\end{tabular}




\begin{tabular}{|c|c|}
\hline Ejes de análisis & Economía Circular y Verde \\
\hline \multicolumn{2}{|r|}{ Generación de valor } \\
\hline $\begin{array}{l}\text { Impulso / } \\
\text { liderazgo }\end{array}$ & $\begin{array}{l}\text { En Europa, la Fundación Ellen MacArthur, junto a estudios de } \\
\text { McKinsey y Sun, es la que está generando los principales estu- } \\
\text { dios e informes sobre la materia. } \\
\text { La Comisión Europea, y en consecuencia, los estados, han to- } \\
\text { mado el compromiso de impulsar la Economía Circular, y en ese } \\
\text { sentido, recientemente se celebró el Foro Mundial de Economía } \\
\text { Circular en Helsinki. } \\
\text { Respecto a la Economía Verde, como ya se ha mencionado, es } \\
\text { una iniciativa de Naciones Unidas (a través del PNUMA). El } \\
\text { término ha sido "adoptado» por empresas e instituciones, a veces } \\
\text { con usos y significados diversos, lo cual ha dado lugar a cierta } \\
\text { mala imagen del término «verde». }\end{array}$ \\
\hline $\begin{array}{l}\text { Relaciones } \\
\text { de poder / } \\
\text { gobernanza }\end{array}$ & $\begin{array}{l}\text { La Fundación Ellen MacArthur afirma que la Economía Cir- } \\
\text { cular es una oportunidad, tanto para empresas con presencia en } \\
\text { gran parte de la cadena de valor (por tanto, empresas grandes), } \\
\text { como para pequeñas empresas y nuevos emprendimientos. } \\
\text { Por otra parte, la colaboración entre sectores y actividades y en- } \\
\text { tre agentes gubernamentales resulta clave para el éxito del mo- } \\
\text { delo. Por tanto, será necesaria una gobernanza multi-nivel y } \\
\text { planteamientos colaborativos-participativos para llegar a acuer- } \\
\text { dos entre partes. } \\
\text { Sin embargo, no hemos encontrado mención expresa a este } \\
\text { asunto. } \\
\text { En lo relativo a la Verde, el planteamiento es de «abajo a arriba» } \\
\text { y no se dice nada sobre la participación de la población local en } \\
\text { las decisiones. }\end{array}$ \\
\hline Escalabilidad & $\begin{array}{l}\text { La economía circular es aún muy minoritaria, pero se presenta } \\
\text { como un modelo a adoptar de forma generalizada, comen- } \\
\text { zando con los sectores prioritarios (donde más margen de me- } \\
\text { jora existe). } \\
\text { Teóricamente, los modelos de negocio son replicables y tam- } \\
\text { bién escalables. Además, se busca una transición de toda (o gran } \\
\text { parte) de la economía, del modelo lineal a uno más circular. Es } \\
\text { por ello que lo hemos catalogado como «modelo socio-econó- } \\
\text { mico» y no únicamente como «modelo de empresa». }\end{array}$ \\
\hline
\end{tabular}




\begin{tabular}{c|l}
\hline \multicolumn{1}{c|}{ Ejes de análisis } & \multicolumn{1}{c}{ Economía Circular y Verde } \\
\hline \multirow{5}{*}{$\begin{array}{c}\text { Valoración } \\
\text { desde la ESS }\end{array}$} & $\begin{array}{l}\text { Generación de valor } \\
\text { La Economía Verde, con su enfoque para los países en vías de } \\
\text { desarrollo, cumple con los principios de equidad (busca reducir } \\
\text { la pobreza), trabajo, sostenibilidad ambiental y compromiso con } \\
\text { el entorno. } \\
\text { Además, la Economía Circular, por su visión sistémica y nece- } \\
\text { sidad de colaboración entre agentes, cumpliría con el principio } \\
\text { equidad, tampoco sobre la orientación al lucro. }\end{array}$ \\
& $\begin{array}{l}\text { Creemos que la Economía Social y Solidaria, fiel a sus principios } \\
\text { y filosofía, puede «adoptar» estar formas de economía circular y } \\
\text { verde, constituyendo un ámbito interesante para la innovación y } \\
\text { la generación de nuevas actividades }{ }^{26} .\end{array}$ \\
\hline
\end{tabular}

\section{Ecosistema de las Nuevas Economías Transformadoras}

En base a la categorización que hemos llevado a cabo para cada movimiento, vamos a hacer análisis conjunto en base a dichas categorías.

\section{Movimientos que hemos categorizado como modelos socio-económicos}

-Economía Solidaria.

- Economía del Bien Común.

-Economía Circular y Verde.

Estas tres propuestas buscan cambiar las bases del sistema socio-económico, desde un nivel macro-económico.

La Economía Solidaria y la Economía del Bien Común se constituyen como propuestas alternativas al sistema capitalista, y complementarias entre sí. Ambas trabajan una triple dimensión: teórica, política y organizativa (praxis). La Economía del Bien Común, al tratarse de un planteamiento

26 De hecho, existen casos reales. Koopera, una cooperativa de segundo grado en la que participan Cooperativas de Iniciativa Social y Empresas de Inserción impulsadas por Cáritas. Su objetivo es la inserción sociolaboral de personas en situación o riesgo de exclusión social, mediante actividades de servicios ambientales, reutilización y reciclaje, upcycling, consumo sostenible, formación, etc. 
nacido hace pocos años, tiene un menor desarrollo en el ámbito político y de praxis, mientras la Solidaria presenta mayor recorrido en sus planteamientos y prácticas reales.

Por su parte, la Economía circular y verde se centran en el plano teórico y organizativo. La economía circular y verde buscan «corregir»el sistema capitalista incorporando la concepción de los límites biofísicos del planeta. De esta forma, presentan una mayor neutralidad política, frente a los planteamientos más críticos de la Economía Solidaria (ES) y la Economía del Bien Común (EBC).

Aun considerando que la ES y la EBC son complementarios, existen algunas diferencias de calado que conviene señalar, tal y como señalan Gómez Calvo y Gómez-Álvarez Díaz (2016):

-El modelo de empresa y primacía del capital. Ambos movimientos coinciden en el papel subordinado del capital, entendiendo que el beneficio es un medio al servicio de un fin, que es el bien común. Pero la EBC no delimita la forma jurídica, ni propone ninguna forma nueva. Simplemente entiende que cambiando las reglas del juego (incentivos) y orientando las empresas hacia el Bien Común, éstas tendrán un comportamiento diferente. En este aspecto la ES establece una frontera clara acerca del tipo de organizaciones que encajan en dicho movimiento, es decir, aquellas que cumplen los 6 principios de la ES, incluido el principio de ausencia de lucro.

- La fuerza impulsora del cambio y la escala. La ES busca fortalecerse a través de la creación de redes de solidaridad y del mercado social, mientras la EBC buscar crear un mercado ético a través de un marco de incentivos institucionales. Por tanto, el planteamiento es más «de arriba abajo». La ES busca actuar en una escala más local, de proximidad, y la EBC busca un cambio a escala global.

-El sector público. Ambas propuestas proponen rediseñar el papel del sector público. Para ambas corrientes, el sector público no debe limitarse a corregir "fallos del mercado", sino que debe ser co-creador de otro tipo de mercado. La ES propone la aplicación de cláusulas sociales para sus organizaciones. Por su parte, la EBC propone transformar todo el mercado a través del nuevo sistema de incentivos. Ambos movimientos abogan por un fortalecimiento de la democracia.

Por su parte, la Economía Circular y Verde, dada su «neutralidad» política, presentan bases teóricas muy interesantes para la Economía Solidaria y la Economía del Bien Común, ya que estas últimas buscan favorecer y cuidar el capital natural, pero no dicen cómo hacerlo. 
Movimientos que hemos categorizado como modelos de empresa y/o modelos de negocio

-Economía Social.

-Empresa Social.

-Economías Colaborativas.

-Economía Circular y Economía Verde.

Mientras las dos primeras hacen referencia a la forma jurídico-organizativa, la misión de la empresa y el destino de los resultados, las dos últimas se refieren al modelo de negocio o forma de combinar los recursos de forma más eficiente. Por tanto, podríamos encontrar empresas de economía social y empresas sociales que lleven a cabo actividades de economía colaborativa, circular o verde.

Se han identificado elementos de confluencia interesantes entre la economía colaborativa y la circular-verde:

- Cambio en los patrones de consumo, donde se prioriza el acceso o servicio frente a la propiedad. Este ha sido uno de los elementos que han impulsado la economía colaborativa, pero es muy interesante también de cara a favorecer una mayor circularidad de la economía. Surgen nuevos modelos de negocio que se basan en la venta por uso, modelo que se denomina «economía de la funcionalidad».

- Uso de plataformas tecnológicas para intercambio de información. Lograr una mayor circularidad de la economía exige disponer y compartir información, no sólo entre particulares, también entre empresas. La economía circular requerirá sistemas colaborativos para intercambiar información entre sectores, facilitar la intermediación, organizar la recogida, reparación y reutilización de recursos, los sistemas de logística inversa, etc.

En lo relativo a las formas jurídico-administrativas, el debate que surge es dónde poner el foco, en la forma jurídica o en el funcionamiento y la misión social que cumple la entidad. A nuestro juicio, sería más interesante el segundo aspecto, siendo la forma jurídica una herramienta al servicio del proyecto empresarial. Las formas de empresa social, a priori, son más flexibles y pueden albergar mayor tipología de proyectos, fomentando el emprendimiento social. Por su parte, los proyectos cooperativos, son fórmulas que garantizan estatutariamente formas de trabajo más democráticas y poder distribuido, aunque su aplicación presenta dificultades en proyectos de crecimiento empresarial ${ }^{27}$.

${ }^{27}$ Citamos aquí nuevamente el trabajo de Igor Ortega (véase cita n. ${ }^{\circ} 12$ ). 
Movimientos que hemos categorizado como sistema de certificación y/o auditoría de empresa

- Economía Solidaria, a través de la Auditoría Social.

- El Certificado B-Corporation, para empresas sociales.

- Economía del Bien Común, a través del Balance del Bien Común.

La Auditoría Social es la herramienta desarrollada por REAS para que las entidades de Economía Solidaria tengan una herramienta de medición de su impacto social. Los objetivos de esta auditoría son tanto internos, para el seguimiento y mejora de la gestión, como externos, para la comunicación a los agentes de los logros de la entidad. Los indicadores están clasificados en base a los 6 principios de la Economía Solidaria, se aplica de forma voluntaria, sin intermediación de auditores externos, y no tiene efectos normativos.

Por su parte, el Balance del Bien Común tiene rasgos similares a los de la Auditoría Social, pero es más abierto en cuanto que puede ser aplicado por empresas de todo tipo, e incluso municipios o regiones. En un plano teórico, la Economía del Bien Común busca cambiar el sistema de incentivos, así como la concepción de éxito de una empresa. La idea de Felber sería establecer un sistema de incentivos a las empresas con el mejor Balance del Bien Común. Por tanto, su objetivo no sería únicamente de mejora y comunicativo (como lo es a día de hoy), sino que tendría consecuencias para las empresas, y con ello se modificaría el comportamiento de las mismas, orientándolas hacia el Bien Común.

Por último, el certificado B-Corps es un sello para el cual la empresa debe lograr una puntuación mínima (de 80 sobre 200) entre todos los indicadores. Es también un instrumento de mejora y de comunicación, y puede ser utilizado de forma voluntaria. La principal diferencia respecto al Balance del Bien Común es que, para obtener y poder utilizar el sello oficial B-Corps, la empresa debe contratar un proceso de auditoría externa. Y también hay una diferencia importante, y es que en el planteamiento de las B-Corps es el mercado el que, a través del sello, valorará la contribución de la empresa haciéndola más competitiva. Por su parte, la ambición de la EBC es mucho más amplia y más utópica. En consecuencia, la EBC propone alcanzar la certificación de territorios, municipios, administraciones públicas y empresas, es decir, todo tipo de organizaciones, mientras B-Corps se centra básicamente en empresas del sector privado. 
Esquema de las Nuevas Economias Transformadoras

A continuación, mostramos un esquema para interpretar todo este ecosistema de economías transformadoras. Se trata de un esquema inspirado en otro similar elaborado por Álvaro Porro para su artículo "¿Qué son las otras Economías?» ${ }^{28}$. Se han utilizado los mismos ejes para clasificar cada movimiento, pero hemos incluido en el esquema únicamente los movimientos analizados en este trabajo, localizándolos en el esquema en base a las conclusiones obtenidas en esta investigación.

El eje horizontal marca el nivel de compromiso en referencia a minimizar o internalizar el impacto social y ecológico de la actividad productiva. El eje vertical marca el compromiso en referencia a generar estructuras de reparto de poder, valor y rendimiento más distribuidas o democráticas.

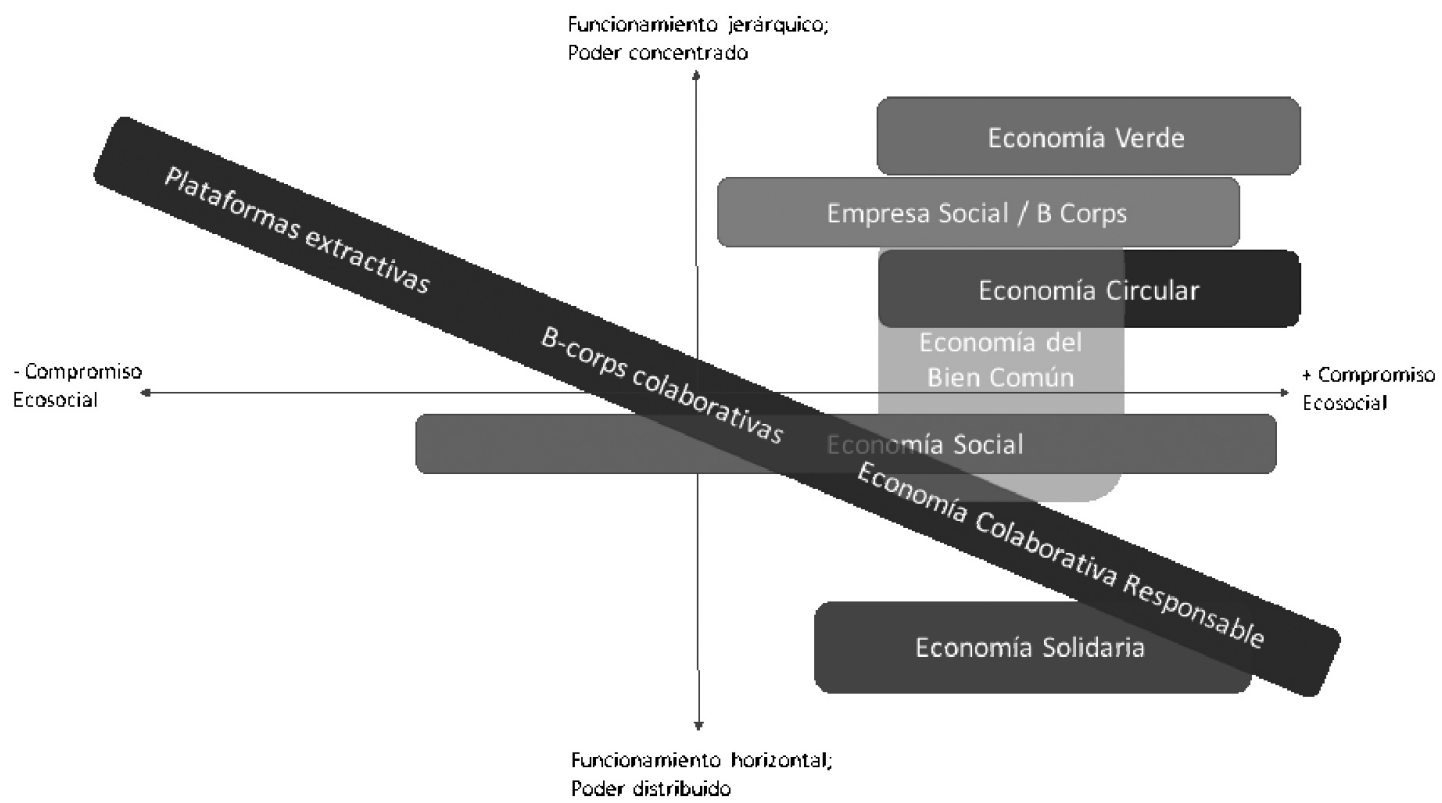

Fuente: elaboración propia, a partir del esquema de Alvaro Porro (2016).

\section{Esquema de las nuevas economías transformadoras}

Como se observa en la imagen, los movimientos analizados, en su mayoría aparecen reflejados en los cuadrantes de la derecha (mayor compromiso ecosocial). Por tanto, confirmamos que se trata de movimientos que buscan responder a los grandes retos sociales y medioambientales actuales.

28 Véase en http://www.eldiario.es/catalunya/opinions/OtrasEconomias_6_493860639. html (publicado en marzo de 2016). 
Los que quedan hacia el lado izquierdo son, en primer lugar, las formas más extractivas de la economía colaborativa. Se trata de aquellas que están generando mayor controversia. Son grandes corporaciones que, aprovechando las nuevas formas de consumo y el auge de las nuevas tecnologías, han creado grandes plataformas que carecen de compromiso ecosocial. Estas corporaciones aprovechan las lagunas legales existentes en este nuevo sector para generar grandes plusvalías a través de la ingeniería fiscal (apenas pagan impuestos), la precarización de su fuerza laboral (no los consideran empleados) y los nuevos patrones de consumo (la idea de "compartid, y mientras, nos forramos ${ }^{29}$ ).

También hemos localizado en el lado izquierdo algunas formas de economía social que, bajo el paraguas de determinada forma jurídica, funcionan con parámetros de mercado, obtención de lucro, y han diluido sus principios de transformación social. No obstante, el grueso se encontraría en el lado derecho.

Fijándonos ahora en el eje vertical, relativo al funcionamiento más o menos horizontal y distribuido, vamos a justificar su localización. Se ha localizado arriba la Economía Verde, por tratarse de un planteamiento institucional (el PNUMA), que es quien elabora la estrategia y propone los pasos para su implantación.

En las empresas sociales y la economía circular, la iniciativa surge de los propios emprendedores que, aunque adopten formas de empresa tradicional, incorporan en la toma de decisiones a diversos agentes (stakeholders). Por tanto, el poder no se distribuye de forma estatutaria, pero hay agentes con capacidad de influencia en la toma de decisiones.

La Economía del Bien Común se sitúa en un punto intermedio. Su enfoque es más institucional que el de la economía social y solidaria, pero es importante señalar que las propuestas de Felber buscan una mayor democratización de la economía. La idea del pueblo soberano y las convenciones, donde se tomarán decisiones clave tales como los límites a la riqueza, brechas salariales máximas y el reparto del trabajo (año sabático, etc.), e incluso la creación de una banca democrática, son claras propuestas de reparto de poder. Sus planteamientos están en un plano más macro-económico, pero no cabe duda que van hacia la dirección de un poder más distribuido ${ }^{30}$.

Para finalizar, encontramos las formas de Economía social en el lado de mayor horizontalidad y poder distribuido, y más abajo aún, las formas de

29 Título del artículo de Ricard Ruiz de Querol en la revista Alternativas Económicas n. ${ }^{\circ} 42$.

30 Por estas razones, hemos colocado la Economía del Bien Común más abajo en el eje que en el esquema de Álvaro Porro. 
Economía solidaria, que promueven formas de organización asamblearias, la participación desde el ámbito local y las relaciones de proximidad.

\section{Conclusiones}

Nos encontramos en un período de grandes cambios e innovaciones, también en lo relativo a la economía y los modelos de negocio. La necesidad de transitar hacia un sistema socio-económico que cuide las personas y el planeta, que se base en otros parámetros más humanos, junto a las oportunidades que ofrecen las nuevas tecnologías y la innovación social, ha provocado que hayan proliferado nuevos modelos y alternativas.

Este artículo se ha centrado en analizar algunos de ellos en base a los criterios de su carácter transformador y la existencia tanto de un marco teórico como de prácticas y proyectos reales suficientemente desarrollados.

Desde la visión de la Economía Social y Solidaria, la economía debe satisfacer las necesidades básicas de las personas de forma eficiente (valor económico), preservando el medioambiente (valor medioambiental), y promoviendo valores de justicia y equidad (valor social).

Se desprende del análisis de las fichas elaboradas que probablemente ninguna de las propuestas analizadas tiene posibilidades de constituirse como una alternativa integral al sistema socio-económico actual. Sin embargo, cada una de las nuevas economías analizadas ofrece respuestas innovadoras a diferentes dilemas del actual paradigma, y se observan además, elementos de complementariedad entre los diferentes modelos.

La Economía Social es la que mayor bagaje y recorrido tiene, así como el mayor peso en la economía real. Se constata que es un modelo que genera una mayor cohesión social, y es resiliente ante las crisis económicas, es decir, que tiene una mayor capacidad de mantener el empleo y el arraigo de la empresa con el territorio. Sin embargo, como modelo empresarial, presenta limitaciones y problemas cuando los proyectos adquieren determinada escala. Por un lado, los proyectos de economía social tienen dificultades de financiar grandes inversiones y acometer ampliaciones de capital, ya que la propiedad es de los trabajadores. Por otra parte, la toma de decisiones complejas resulta complicada por parte de los trabajadores, que pueden no estar preparados para tomar decisiones estratégicas de la empresa.

La Economía Solidaria presenta una importante dinámica innovadora, siendo capaz de generar nuevas actividades en sectores complejos, como las finanzas, la energía, las telecomunicaciones, etc. Sin embargo, se rige por una serie de principios que la convierten por definición en un planteamiento exigente y minoritario. 
Los planteamientos de las empresas sociales (incluidas las B-Corps) pueden abarcar todo tipo de actividades y dimensiones empresariales, a la vez que resuelven problemas sociales. Sin embargo, no queda claro cuál es la fuerza que les impulsa a la transformación social, más allá de los beneficios en términos de reputación y el compromiso de sus stakeholders con el proyecto. No se puede esperar que sea "el mercado» quien evalúe y valore dicha transformación, y de forma casi automática, la economía y las empresas se vuelvan justas y éticas. En este sentido la Economía del Bien Común hace una aportación fundamental, al proponer toda una serie de mecanismos institucionales y democráticos que aseguren un funcionamiento distinto de la economía, pero no explica cómo llevar a cabo dicha transición.

Se ha concluido que la Economía del Bien Común (EBC) y la Economía Solidaria (ES) son propuestas complementarias. La EBC plantea una transformación a escala global de la economía con un nuevo marco de incentivos que impulsen a toda la economía hacia el bien común. Por su parte, la ES tiene la capacidad de organizarse y llevar a la práctica propuestas innovadoras desde lo local.

La Economía Colaborativa es la que está experimentando un crecimiento exponencial, llegando a actividades y volúmenes inesperados, y a su vez, es la que mayor controversia está generando. En este trabajo se ha detectado un ámbito de oportunidad para la ESS de cara a democratizar el control y propiedad de las plataformas, que es la idea del «cooperativismo de plataforma» desarrollado por Trebor Scholz.

Se han detectado puentes clarísimos entre la economía colaborativa y la economía circular-verde. La creación de plataformas para aumentar el uso de productos compartiendo su empleo, acceso o propiedad será un modelo de negocio de la economía circular. Las plataformas tienen la virtualidad de generar un uso más eficiente de los recursos, pero es necesaria una conciencia medio-ambiental para que no se produzca un efecto rebote. Y los modelos de economía circular-verde necesitaran plataformas tecnológicas para desarrollar todo su potencial.

Tratándose la mayoría de ellos de modelos emergentes, hemos detectado la importancia de gestionar la transición de un modelo hacia otro. El cambio de un paradigma a otro hace que unos sectores ganen y otros pierdan, aunque el resultado final esperado sea mejor. Las transiciones generan unos costes que hay que considerar. También hay que tener en cuenta que los avances tecnológicos y las nuevas realidades plantean escenarios sobre los que se deben tomar decisiones políticas (cambios legislativos, normativos...) que suelen tardar demasiado tiempo en materializarse. La orientación que tomen dichas decisiones políticas favorecerá un modelo u otro. Sería deseable que dichas decisiones favorezcan aquellos modelos con más compromiso social y medioambiental. 
Desde la visión de la Economía Social y Solidaria, consideramos que todos los modelos y propuestas emergentes pueden ser «adoptados» o apropiados por la ESS y que, por tanto, estos modelos constituyen una fuente clarísima de innovación para este sector.

Con la mirada puesta hacia el futuro, y tratándose de modelos y alternativas incipientes, hemos observado que existe aún un conocimiento y análisis limitado sobre los mismos. Por lo general, no se cuenta con análisis estadísticos y existen, en algunos casos, estudios prospectivos e hipótesis sobre lo que supondría la aplicación generalizada de uno u otro modelo. Constituyen, por tanto, un campo interesante para el análisis y realización de estudios académicos, para la experimentación práctica de los modelos, así como para el debate político y social.

\section{Bibliografía}

Cañigeral, A. (2016). Hacia una economía colaborativa «responsable. Revista OIKONOMICS n. ${ }^{\circ}$ 6, noviembre 2016. Disponsible en línea: http://oikonomics. uoc.edu/divulgacio/oikonomics/es/numero06/dossier/acanigueral.html

Campos-I-Climent, V. (2016). «La economía social y solidaria en el siglo XXI: un concepto en evolución. Cooperativas, B-corps y economía del bien común». Revista OIKONOMICS n. ${ }^{\circ}$ 6, noviembre 2016. Disponsible en línea: http:// oikonomics.uoc.edu/divulgacio/oikonomics/es/numero06/dossier/vcampos. html

Comisión Europea (2015). Comunicación de la Comisión al Parlamento Europeo, al Consejo, al Comité Económico y Social Europeo y al Comité de las Regiones, "Cerrar el circulo: un plan de acción de la UE para la economía circular» Disponible en: http://eur-lex.europa.eu/resource.html?uri=cellar:8a8ef5e899a0-11e5-b3b7-01aa75ed71a1.0011.02/DOC_1\&format=PDF

Comité Económico y Social Europeo (2015). «Dictamen del Comité Económico y Social Europeo sobre el tema "La Economía del Bien Común: un modelo económico sostenible orientado a la cohesión social» Disponible en línea: http://eur-lex. europa.eu/legal-content/ES/TXT/PDF/?uri=CELEX:52015IE2060\&from=ES

Comité Económico y Social Europeo (2014). «Dictámen sobre Consumo colaborativo o participativo: un modelo de sostenibilidad para el siglo XXI» Disponible en: http://eur-lex.europa.eu/legal-content/ES/TXT/PDF/?uri=CELEX:52013IE2 $788 \&$ from $=\mathrm{ES}$

Comité Económico y Social Europeo (2017). «Recent evolutions of the Social Economy in the European Union» Disponible en: http://www.eesc.europa.eu/ en/our-work/publications-other-work/publications/recent-evolutions-socialeconomy-study

Economía del Bien Común. Web del movimiento en español: http://economiadel-bien-comun.org. Documentos obtenidos: Breve presentación de la Eco- 
nomía del Bien Común, disponible en: http://economia-del-bien-comun. org/sites/default/files/A4_EBC_Esp12.pdf; Matríz del Bien Común 4.1. (2014) Disponible en: http://economia-del-bien-comun.org/sites/default/files/ Matriz\%20del\%20bien\%20com\%C3\%BAn\%204.1.pdf

European Environment Agency, Briefing «Green Economy» (2017), disponible en: https://www.eea.europa.eu/soer-2015/europe/green-economy

Eusko Ikaskuntza (2016). La(s) transición(es) hacia otra(s) economia(s) Disponible en línea: http://www.euskonews.com/0716zbk/argazkiak/La(s)\%20 transicion(es)\%20hacia\%20otra(s)\%20economia(s).pdf

Eusko Ikaskuntza (2017). Conclusiones Seminario Nuevas Economias Disponible en línea: http://www.euskonews.com/0716zbk/argazkiak/conclusiones_II_ seminario_economia.pdf

Felber, C. (2012). La Economía del Bien Común Ediciones Deusto.

Fundación Ellen MacArthur (2015) «Hacia una economía circular: motivos económicos para una transición acelerada». Disponible en: https://www.ellenmacarthurfoundation.org/assets/downloads/publications/Executive_summary_SP.pdf

Gómez Calvo, V. \& Gómez-Alvarez Díaz, R. (2016). La economía del bien común y la economía social y solidaria ¿son teorias complementarias?, CIRIEC-España, Revista de Economía Pública, Social y Cooperativa n. ${ }^{\circ}$ 87/2016.

NESI Forum (2017). Carta de Málaga. Disponible en: http://neweconomyforum. org/CartadeMalaga.pdf

New Economics Foundation (2016). "Building a new economy where people really take control. An agenda for change» Disponible en: http://neweconomics.org/ wp-content/uploads/2016/10/BUILDING_A_NEW_ECONOMY.pdf

OCU, Universidad Complutense de Madrid y Ouishare (2015). "Colaboración o negocio. Consumo colaborativo: del valor para el usuario a una sociedad con valores» Informe publicado en OCU-Compra Maestra (OCU-CM n.o 409, diciembre 2015, y OCU-CM n. ${ }^{\circ} 410$, enero 2016) y en Dinero y Derechos n. ${ }^{\circ}$ 153, marzo 2016. Informe en inglés y resúmen ejecutivo disponible en: https://www.ocu.org/organizacion/que-hacemos/nuestras-acciones/2016/ informe-ocu-economia-colaborativa

Pérez de Mendiguren, J.C.; Etxezarreta, E. \& Guridi, L. (2012). Economía Social, Empresa Social y Economía Solidaria: diferentes conceptos para un mismo debate, Papeles de Economía Solidaria n. ${ }^{\circ} 1$ REAS.

Porro, A. (2017). ¿Qué son las economias transformadoras? Publicado en diferentes blogs: http://opcions.org/es/blog/que-son-las-economias-transformadoras. Otra versión similar se publicó en: http://www.eldiario.es/catalunya/opinions/ OtrasEconomias_6_493860639.html

Programa de Naciones Unidas para el Medio Ambiente (2011). Hacia una economía verde-Guía para el desarrollo sostenible y la erradicación de la pobreza. Disponble en: http://www.paho.org/mex/index.php?option=com_docman\&view=download\&category_slug=promocion-de-la-salud-yreduccion-de-riesgos \&alias=376-hacia-una-economia-verde-guia-para-eldesarrollo-sostenible-y-la-erradicacion-de-la-pobreza\&Itemid=493 
REAS. Red de redes de economía alternativa y solidaria (2011). Carta de la Economía Solidaria. Disponible en línea: http://www.economiasolidaria.org/files/ CARTA_ECONOMIA_SOLIDARIA_REAS.pdf

Scholz, T. (2016). "Cooperativismo de Plataforma». Dimmons - Investigación acción en producción procomún. Internet Interdisciplinary Institute (IN3) Universitat Oberta de Catalunya (UOC). Disponible en: http://rosaluxspba. org/wp-content/uploads/2016/06/maq_Trebor-Scholz_COOP_PreF_DP.pdf 